\title{
Comprehensive investigation of low salinity waterflooding in carbonate reservoirs
}

\author{
M. Fouad Snosy ${ }^{1} \cdot$ Mahmoud Abu El Ela ${ }^{2} \cdot$ Ahmed El-Banbi $^{3} \cdot$ Helmy Sayyouh ${ }^{2}$
}

Received: 25 August 2021 / Accepted: 12 October 2021 / Published online: 21 October 2021

(c) The Author(s) 2021

\begin{abstract}
Waterflooding has been practiced as a secondary recovery mechanism for many years with no regard to the composition of the injected brine. However, in the last decade, there has been an interest to understand the impact of the injected water composition and the low salinity waterflooding (LSWF) in oil recovery. LSWF has been investigated through various laboratory tests as a promising method for improving oil recovery in carbonate reservoirs. These experiments showed diverse mechanisms and results. In this study, a comprehensive review and analysis for results of more than 300 carbonate core flood experiments from published work were performed to investigate the effects of several parameters (injected water, oil, and rock properties along with the temperature) on oil recovery from carbonate rock. The analysis of the results showed that the water composition is the key parameter for successful waterflooding (WF) projects in the carbonate rocks. However, the salinity value of the injected water seems to have a negligible effect on oil recovery in both secondary and tertiary recovery stages. The study indicated that waterflooding with optimum water composition can improve oil recovery up to $30 \%$ of the original oil in place. In addition, the investigation showed that changing water salinity from LSWF to high salinity waterflooding can lead to an incremental oil recovery of up to $18 \%$ in the tertiary recovery stage. It was evident that applying the optimum composition in the secondary recovery stage is more effective than applying it in the tertiary recovery stage. Furthermore, the key parameters of the injected water and rock properties in secondary and tertiary recovery stages were studied using Fractional Factorial Design. The results revealed that the concentrations of $\mathrm{Mg}^{2+}, \mathrm{Na}^{+}, \mathrm{K}^{+}$, and $\mathrm{Cl}^{-}$in the injected water are the greatest influence parameters in the secondary recovery stage. However, the most dominant parameters in the tertiary recovery stage are the rock minerals and the concentration of $\mathrm{K}^{+}, \mathrm{HCO}_{3}{ }^{-}$, and $\mathrm{SO}_{4}{ }^{2-}$ in the injected water. In addition, it appears that the anhydrite percentage in the carbonate reservoirs may be an effective parameter in the tertiary WF. Also, there are no clear relations between the incremental oil recovery and the oil properties (total acid number or total base number) in both secondary and tertiary recovery stages. In addition, the results of the analysis showed an incremental oil recovery in all ranges of the studied flooding temperatures. The findings of this study can help to establish guidelines for screening and designing optimum salinity and composition for WF projects in carbonate reservoirs.
\end{abstract}

Keywords Low salinity waterflooding $\cdot$ Carbonate reservoirs $\cdot$ Smart waterflooding $\cdot$ Enhanced oil recovery

$\begin{array}{ll}\text { Abbreviations } \\ \text { EOR } & \text { Enhanced oil recovery } \\ \text { FFD } & \text { Fractional factorial design } \\ \text { HS } & \text { High salinity water } \\ \text { HSWF } & \text { High salinity waterflooding }\end{array}$

M. Fouad Snosy

mfsnosy@yahoo.com

1 Petroleum Engineer, General Petroleum Company, Cairo, Egypt

2 Faculty of Engineering, Cairo University, Cairo, Egypt

3 Petroleum and Energy Engineering, The American University in Cairo, Cairo, Egypt

$\begin{array}{ll}\text { IFT } & \text { Interfacial tension } \\ \text { Incr. } & \text { Incremental } \\ \text { LS } & \text { Low salinity water } \\ \text { LSWF } & \text { Low salinity waterflooding } \\ \text { MIE } & \text { Multi-component ion exchange } \\ \text { NA } & \text { Not available } \\ \text { OOIP } & \text { Original oil in place } \\ \text { Sec. } & \text { Secondary recovery stage } \\ \text { TAN } & \text { Total acid number } \\ \text { TBN } & \text { Total base number } \\ \text { TDS } & \text { Total dissolved salts } \\ \text { Ter. } & \text { Tertiary recovery stage } \\ \text { WF } & \text { Waterflooding }\end{array}$

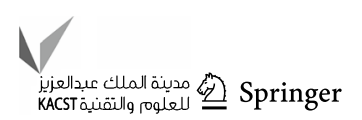




\begin{tabular}{ll}
\multicolumn{2}{l}{ Symbols } \\
$k$ & Permeability, md \\
$K_{\mathrm{a}}$ & Air permeability, md \\
$\mathrm{PV}$ & Pore volume, CC \\
$T$ & Temperature, ${ }^{\circ} \mathrm{C}$ \\
$\alpha$ & Significance level, fraction \\
$\Phi$ & Porosity, fraction
\end{tabular}

\section{Introduction}

LSWF is defined as an enhanced oil recovery method that uses water with a low concentration of dissolved salts and/ or modifying the ionic content of injected brines as a flooding medium (Bartels et al. 2019). The LSWF technique is also known in the literature as low salinity trademark, smart waterflood, designer waterflood, advanced ion management, modified salinity flooding, ion tuning, and engineered water injection.

The LSWF applications revealed several successful results in laboratory experiments for core plugs extracted from carbonate reservoirs. However, the effect of the LSWF in the carbonate reservoirs has not been well studied compared to the sandstone reservoirs (Al Shalabi and Sepehrnoori 2017). It should be highlighted that Bagci et al. (2001) conducted the first core flooding experiments on carbonate reservoirs. They reported $18.8 \%$ higher oil recovery by injecting $2 \% \mathrm{KCl}$ plus $2 \% \mathrm{NaCl}$ brine mixture rather than injecting other brine compositions. The LSWF showed incremental oil recovery up to $20 \%$ higher than the HSWF (Strand et al. 2008; Ligthelm et al. 2009; Yousef et al. 2011). In other studies, Shariatpanahi et al. (2011), Fathi et al. (2010), and Zekri et al. (2019) documented additional oil recovery up to $11 \%$ by injecting sea water in carbonate core plugs. They reported that sea water with high sulfate concentrations could increase oil recovery from the carbonate reservoirs.

The most acceptable mechanism of the LSWF in the carbonate reservoirs is the wettability change (Yousef et al. 2011; Al-adasani et al. (2012). However, the explanation of the physical mechanism of changing the wettability is still debated. The proposed mechanisms include fine migration, multi-component ion exchange (MIE), calcite dissolution, interfacial tension (IFT) reduction, double-layer expansion, anhydrite dissolution, salting-in, water micro-dispersion, osmosis pressure effect, and surface roughness.

The fines migration mechanism was initially proposed by Bernard (1967) for sandstone reservoirs. Then, it was accepted by Tang and Morrow (1997). This mechanism was also suggested for the carbonate reservoirs by Yi and Sarma (2012); and Zahid et al. (2012). However, this suggestion was not accepted by Lager et al. (2008), Shaker and Skauge
(2013), Amirian et al. (2017), and others who noticed an increase in the oil recovery without fines migration.

The MIE evidence of the LSWF in the carbonate reservoirs was proposed by Austad et al. (2005). Then, this mechanism was accepted by Strand et al. (2008), Ligthelm et al. (2009), Zhang and Austad (2006), Puntervold (2008), and Myint and Firoozabadi (2015). They suggested that the MIE in the carbonate reservoirs is anion exchange (It is not a cation exchange like sandstone reservoirs).

The calcite dissolution mechanism of the LSWF in the carbonate reservoirs was proposed by Hiorth et al. (2008). Then, in other studies, this mechanism was confirmed by Evje and Hiorth (2010) and Den Ouden et al. (2015). However, Austad et al. (2010), Mahani et al. (2015), and Romanuka et al. (2012) did not accept this mechanism. They documented that no incremental oil recovery is achieved when only sulfate exists with no calcium, while the solubility should increase in the absence of calcium.

The IFT reduction mechanism of the LSWF in the carbonate reservoirs was suggested by McGuire et al. (2005), Vijapurapu and Rao (2003), Okasha and Alshiwaish (2009), and Mohsenzadeh et al. (2016). However, Yousef et al. (2011), Al Harrasi et al. (2012), and Al-Attar et al. (2013) reported that the application of the LSWF in the carbonate reservoirs has an insignificant effect on the IFT.

The water micro-dispersion mechanism of the LSWF in the carbonate reservoirs was proposed by Emadi and Sohrabi (2012). Then, it was documented by Mahzari and Sohrabi (2014), Sohrabi et al. (2017), Alvarado et al. (2014), ChávezMiyauchi et al. (2016), Sarvestani et al. (2019), and Dordzie and Dejam (2021).

The double-layer expansion mechanism of the LSWF in the carbonate reservoirs was suggested by Ligthelm et al. (2009) and accepted by Shariatpanahi et al. (2011), Aladasani et al. (2012), Fathi and Austad (2012), Al-Shalabi et al. (2014), Alameri et al. (2014), Mahani et al. (2015), Sohal et al. (2016), and Liu et al. (2016).

The anhydrite dissolution mechanism of the LSWF in the carbonate reservoirs was proposed by Austad et al. (2011) and Pu et al. (2008) and was agreed by Austad et al. (2015). They believed that it is a method of generating in situ $\mathrm{SO}_{4}{ }^{2-}$ which is thought to act as a catalyst in the wettability alteration process. This mechanism was not accepted by Jiang et al. (2014) and Uetani et al. (2019). Furthermore, Romanuka et al. (2012) and Nasralla et al. (2014) reported that anhydrite dissolution is not considered the primary mechanism for LSWF.

The salting-in mechanism was proposed by Austad et al. (2007) as a result of rock dissolution. The migration of divalent ions from the rock surface toward the brine causes a change in rock wettability.

Osmosis mechanism was suggested by Sandengen and Arntzen (2013) and was agreed by Sandengen et al. (2016), 
Fredriksen et al. (2016), and Fredriksen et al. (2018). However, Bartels et al. showed that the osmosis pressure could contribute to the incremental oil recovery, but it is not the primary mechanism of LSWF (2017).

The surface roughness mechanism of the LSWF in the carbonate reservoirs was investigated by Sari (2020). It was proposed that the contact angle consistently decreased (becomes less oil-wet) with increasing the surface roughness. However, they reported that the effect of surface roughness on contact angle reduces with decreasing brine salinity.

Derkani et al. (2018) supposed that, in general, it is believed that there should be more than one factor in effect for LSWF in carbonate reservoirs. Al-Shalabi et al. (2015) reported that the incremental oil recovery by LSWF in carbonates could best be explained as wettability alteration caused by dissolution, changes in $\mathrm{pH}$, and double-layer expansion.

The above introduction shows that the applications of the LSWF can increase the oil recovery from carbonate reservoirs. However, there is no single opinion on the LSWF mechanisms. In general, there is more than one effective factor and mechanism for the LSWF in the carbonate reservoirs. In addition, there is no agreement on which mechanisms are important and can act under which conditions. Moreover, till now, it has been difficult to accurately predict the effects of the LSWF in the carbonate reservoirs because of the complexity of the chemical interactions between the carbonate rocks and the reservoir fluids, as well as the heterogeneity of the rock. This work is a trial to analyze the results of several core flood experiments from the literature to obtain guidelines for improving oil recovery in typical waterfloods by changing/optimizing water salinity and composition.

Most of the previous work depended on a limited number of core experiments. However, this work included data analysis for results of more than 300 core experiments from the literature. Therefore, the results and the analysis of the current work are reliable. The effects of several parameters (injected water, oil, and rock properties along with the temperature) on oil recovery were studied and investigated. Furthermore, statistical analysis using a two-level folded Plackett-Burman design was performed to identify the most significant parameters relative to incremental oil recovery for carbonate reservoirs in secondary and tertiary recovery stages. However, the dataset range is limited to extract a solid conclusion for the effect of rock minerals on the oil recovery during the secondary recovery stage.

Figure 1 shows a block diagram for the methodology of this work. Initially, the available data and results of published experimental works on carbonate cores were collected and reviewed. Secondly, the database was built, including all rock and fluid properties along with the flooding results. Then, the data and results were analyzed; and relationships between incremental oil recovery, rock, and fluid properties

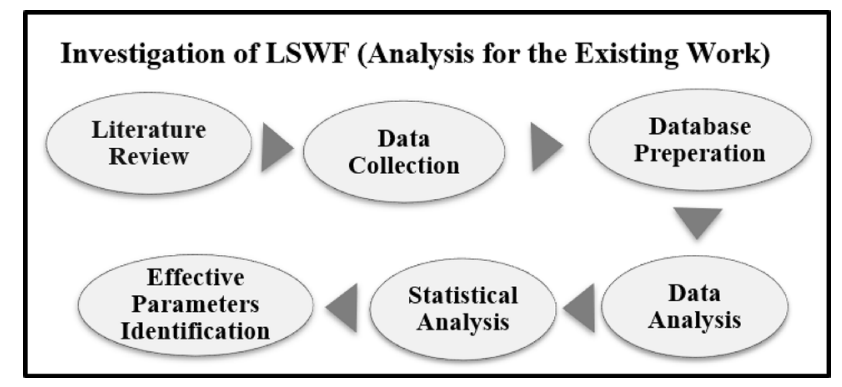

Fig. 1 Block diagram of the methodology

were established. Finally, statistical analysis was performed to identify the most effective oil recovery parameters in both secondary and tertiary recovery stages.

\section{Database of previous flooding experiments}

A database with results of more than 300 core flood experiments of carbonate reservoirs was collected and analyzed from the literature. The analyzed data includes (1) about 200 tertiary law salinity waterflooding experimental runs that have been carried out by more than 100 core plugs, and (2) around 100 secondary waterflooding experimental runs that have been conducted by 50 core plugs approximately. The summary of the collected data, including the main rock characteristics and the core flooding experiments' results, is presented in Table 1.

The histograms of the rock properties (porosity and permeability) and the incremental oil recovery during the secondary and tertiary recovery stages are shown in Fig. 2a-d.

Figure 2a shows that most of the core plugs in the collected dataset cover range of porosity starting from 12 up to $35 \%$. More than $75 \%$ of the core plugs have a porosity range of $15-25 \%$. However, Fig. $2 \mathrm{~b}$ illustrates that the core plugs' maximum permeability in the collected dataset was $470 \mathrm{md}$, while the minimum permeability was $0.2 \mathrm{md}$. It is clear that more than $80 \%$ of the core plugs in the collected data have a permeability of less than $120 \mathrm{md}$. It should be highlighted that less than $50 \%$ of the core plugs in the collected data have a description of the rock minerals.

Figure $2 \mathrm{c}$ demonstrates that the incremental oil recovery achieved from applying the LSWF in the carbonate rock during the secondary recovery stage ranged from -30 to $30 \%$. The negative incremental oil recovery values mean that the application of the LSWF attained less oil recovery than that achieved in the HSWF experiments. The collected data indicate that the maximum additional oil recovery by applying the LSWF during the tertiary recovery stage was about $24 \%$ of the OOIP in most of the experiments. Most of the core plugs showed incremental oil recovery in the tertiary recovery stage, less than $18 \%$, as shown in Fig. 2 d.

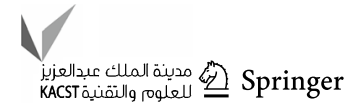


Table 1 Summary of core flood experiments results collected from the literature

\begin{tabular}{|c|c|c|c|c|c|c|c|}
\hline References & Type & No. of plugs & $\mathrm{PV}, \mathrm{CC}$ & $\Phi, \%$ & $K_{\mathrm{a}}, \mathrm{md}$ & $\begin{array}{l}\text { Rock mineral } \\
\text { description }\end{array}$ & $\begin{array}{l}\text { Incr. oil } \\
\text { recovery, \% } \\
\text { OOIP }\end{array}$ \\
\hline \multirow[t]{2}{*}{ AlQuraishi et al. (2015) } & Ter & 1 & 9 & 18 & 206 & Available & (16) \\
\hline & Sec & 1 & 9 & 18 & 206 & Available & $(10)$ \\
\hline Al Hamad et al. (2017) & Ter & 6 & $10-13$ & $17-19$ & $36-127$ & NA & (0)-(17) \\
\hline Tetteh et al. (2017) & Ter & 10 (2 Composite) & $46-66$ & 25 & $60-102$ & NA & $(0)-(10)$ \\
\hline Yousef et al. (2010) & Ter & 2 & 14 & 17 & $23-80$ & NA & $(5)-(11)$ \\
\hline Sari et al. (2017) & Ter & 2 & $9-13$ & $18-23$ & $3-6$ & Available & (6)-(18) \\
\hline Austad et al. (2012) & Ter & 6 & $14-33$ & $16-42$ & $0.2-4$ & Available & $(0)-(5)$ \\
\hline Zahid et al. (2012) & Ter & 6 & $9-24$ & $19-33$ & $3-308$ & NA & $(0)-(12)$ \\
\hline Uetani et al. (2019) & Ter & 6 & $14-21$ & $17-24$ & $2-60$ & Available & $(0)-(7)$ \\
\hline \multirow[t]{2}{*}{ Hamouda and Maevskiy (2014) } & $\mathrm{Sec}$ & 5 & 41 & 49 & 4 & NA & $(-3)-(2)$ \\
\hline & Ter & 1 & 39 & 48 & 4 & NA & $(0)$ \\
\hline Ali et al. (2012) & Ter & 5 (1 Composite) & 88 & 21 & 148 & Available & $(1.5)-(7)$ \\
\hline Romanuka et al. (2012) & Ter & 25 & NA & $12-51$ & $2-235$ & Available & $(0)-(21)$ \\
\hline \multirow[t]{2}{*}{ Gandomkar and Rahimpour. (2015) } & Ter & 12 & $15-19$ & $17-22$ & $2-7$ & Available & $(6)-(35)$ \\
\hline & $\mathrm{Sec}$ & 12 Twins & $15-19$ & $17-22$ & $2-7$ & Available & $(0)$ \\
\hline Aksulu et al. (2012) & Ter & 2 & 17 & 31 & $53-78$ & NA & $(0)-(45)$ \\
\hline \multirow[t]{2}{*}{ Almeida et al. (2019) } & $\mathrm{Sec}$ & 4 Twins & 8 & 15 & $126-160$ & NA & (3)-(10) \\
\hline & Ter & 2 & 8 & 15 & $125-141$ & NA & (7)-(17) \\
\hline Camargo et al (2019) & Ter & 1 & 13 & 21 & 61 & NA & $(17)$ \\
\hline \multirow[t]{2}{*}{ Masalmeh et al. (2019) } & $\mathrm{Sec}$ & 3 & $115-146$ & $19-25$ & $1.6-30$ & NA & $(0)-(12.5)$ \\
\hline & Ter & 3 & $115-146$ & $19-25$ & $1.6-30$ & NA & $(0-(6)$ \\
\hline Bazhanova and Pourafshary (2020) & $\mathrm{Sec}$ & 2 Twin & 15 & 17 & $19-47$ & NA & (5) \\
\hline \multirow[t]{2}{*}{ Abdeli and Seiden (2018) } & $\mathrm{Sec}$ & 8 Twins & $14-20$ & $19-22$ & $0.4-1.7$ & NA & $(-14)-(27)$ \\
\hline & Ter & 6 & $14-20$ & $19-22$ & $0.4-1.7$ & NA & $(4-(12)$ \\
\hline Ghandi et al. (2019) & $\mathrm{Sec}$ & 3 & 4.6 & 18.5 & 25.3 & Available & $(9-(13)$ \\
\hline Zekri et al. (2019) & Ter & 9 & $10-16$ & $17-24$ & $0.2-1.7$ & NA & $(1)-(7)$ \\
\hline \multirow[t]{2}{*}{ Hosseini et al. (2020) } & $\mathrm{Sec}$ & 2 & $13-18$ & $13-17$ & $0.7-1.7$ & Available & $(-2)-(20)$ \\
\hline & Ter & 2 & $13-18$ & $13-17$ & $0.7-1.7$ & Available & $(1)-(10)$ \\
\hline Abdelhamid and Elnaggar. (2017) & Sec & 8 & NA & $19-27$ & $35-471$ & NA & $(-7)-(6)$ \\
\hline \multirow[t]{2}{*}{ Al Harrasi et al. (2012) } & $\mathrm{Sec}$ & 1 & 13 & 25 & 5 & Available & 12 \\
\hline & Ter & 5 & $11-14$ & $22-26$ & 5 & Available & $0-13$ \\
\hline
\end{tabular}

Table 2 presents the devices and measurement methods used in the collected database's experimental work. It is clear that mainly two methods were used to perform the flooding experiments in the secondary and tertiary recovery stages, namely core flooding and spontaneous imbibition methods. The core flooding was applied using a mainly liquid pump, piston cell, core holder, oven, glass beret, and computer-controlled system. However, the spontaneous imbibition method was applied by displacing the fluid with a sealed core holder's pump. In this method, the displaced fluid volume could be measured directly or determined by weight balance measurements. In one of the previous studies using carbonate core plugs, Almeida et al. (2019) studied the effect of the LSWF on oil recovery using a high-speed centrifuge method.
As shown in Table 2, various methods were used in the collected database's experimental work to study the wettability alteration behavior due to the change of the injected water salinity. The wettability indication methods were mainly the measurements of the contact angle, Zeta potential, $\mathrm{pH}$, and interfacial tension. In addition, in some of the experiments, the wettability index was measured using the Amott Harvest method.

\section{Discussion}

\section{Salinity range for the LSWF applications}

There are different opinions in the literature regarding the optimum water salinity range that can improve oil recovery 
Fig. 2 Histograms of porosity, permeability, and incremental oil recovery of the literature data

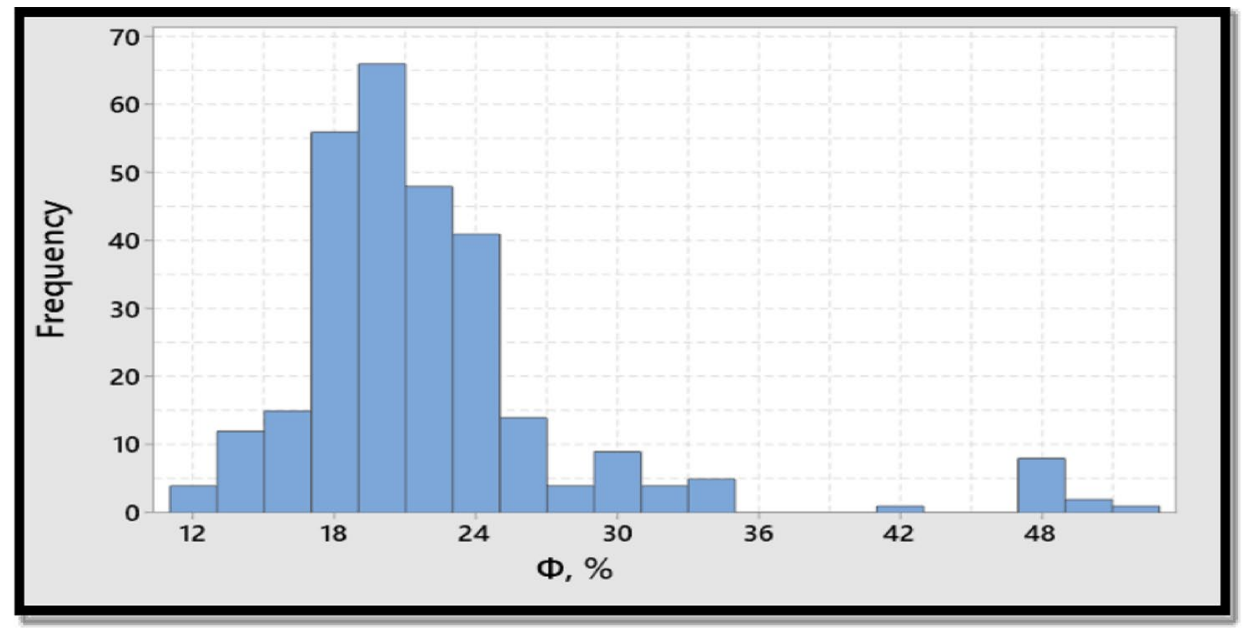

a Histogram of core samples porosity

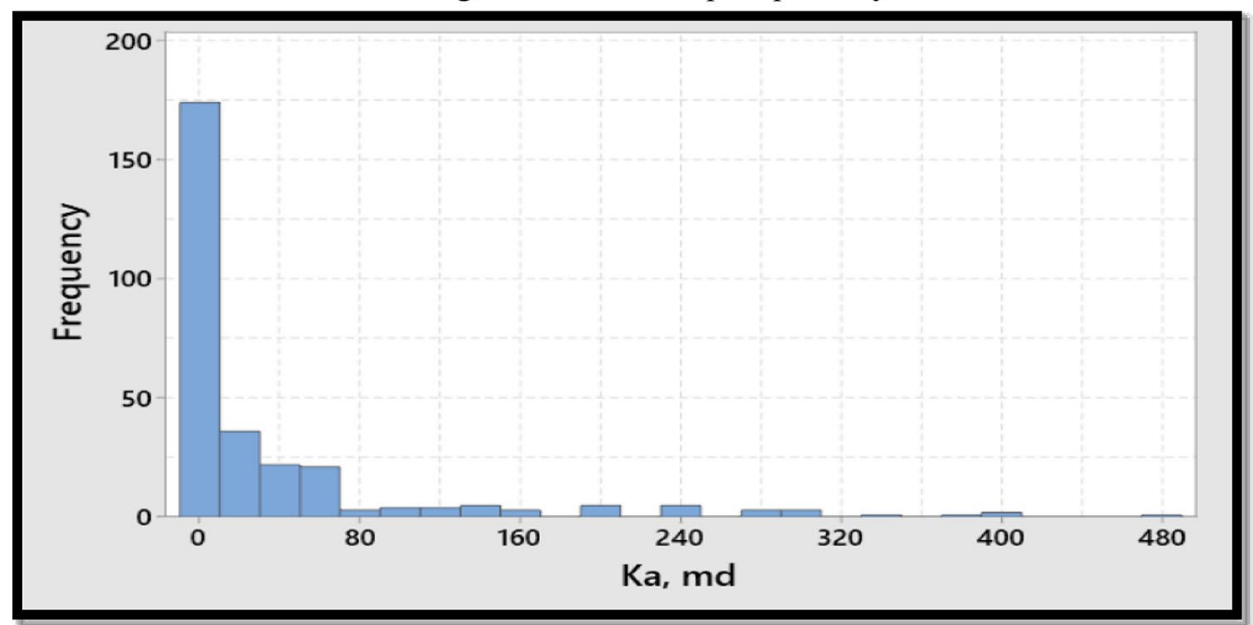

b Histogram of core samples permeability

in carbonate reservoirs. Figure 3 presents the relationship between the injected water salinity and incremental oil recovery during the secondary and tertiary recovery stages.

Figure 3a shows the effect of the water salinity on oil recovery during the secondary recovery stage. When water with a salinity of less than 5000 ppm was used, some flooding experiments showed high incremental oil recovery up to $35 \%$, and others showed lower incremental oil recovery. In addition, when the water of salinity of more than $5000 \mathrm{ppm}$ was used, an incremental oil recovery up to $15 \%$ only was documented and observed in several experiments.

It should be highlighted that Gandomkar and Rahimpour (2015) and Abdeli and Seiden (2018) reported an increase of oil recovery up to $20 \%$ during the secondary WF recovery stage with different water compositions and the same total dissolved salinity (TDS). In addition, Alotaibi and Nasr-ElDin (2019) suggested that there is a critical salinity (not the lowest), at which the IFT between oil and brine is at a minimum level. Snosy et al. (2020) and Snosy et al. (2021) reported the same results from the sandstone reservoir.
Furthermore, the application of the LSWF in the tertiary recovery stage showed various results, as shown in Fig. 3b. Additional oil recovery was achieved in the tertiary recovery stage using water of salinity of more than $20,000 \mathrm{ppm}$. Moreover, no additional oil recovery was observed in other experiments even when WF of water salinity less than $1000 \mathrm{ppm}$ was applied. Aksulu et al. (2012) reported that the incremental oil recovery with the application of the LSWF in the carbonate rock ranges from 0 to more than $30 \%$ using water of a salinity less than $500 \mathrm{ppm}$.

Moreover, Romanuka et al. (2012), Aksulu et al. (2012), and Zekri et al. (2019) reported additional oil recovery in the tertiary recovery stages reached $18 \%$ with applying HSWF after LSWF.

It should be highlighted that application of the WF with optimum composition achieved higher oil recovery in the secondary recovery stage up to $10 \%$ than that obtained during the tertiary recovery stage, as presented by Masalmeh et al. (2019); and Hosseini et al. (2020). However, Al Harrasi et al. (2012) reported that the WF with optimum composition 
Fig. 2 (continued)

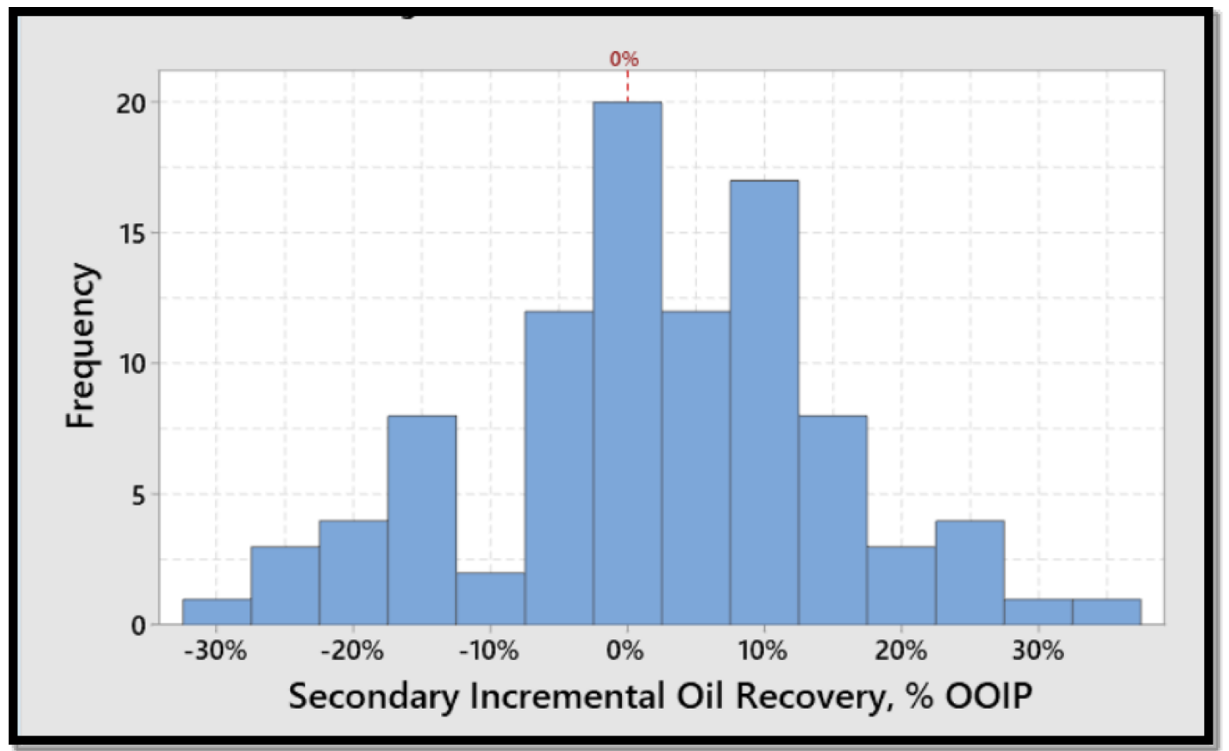

c Histogram of secondary incremental oil recovery

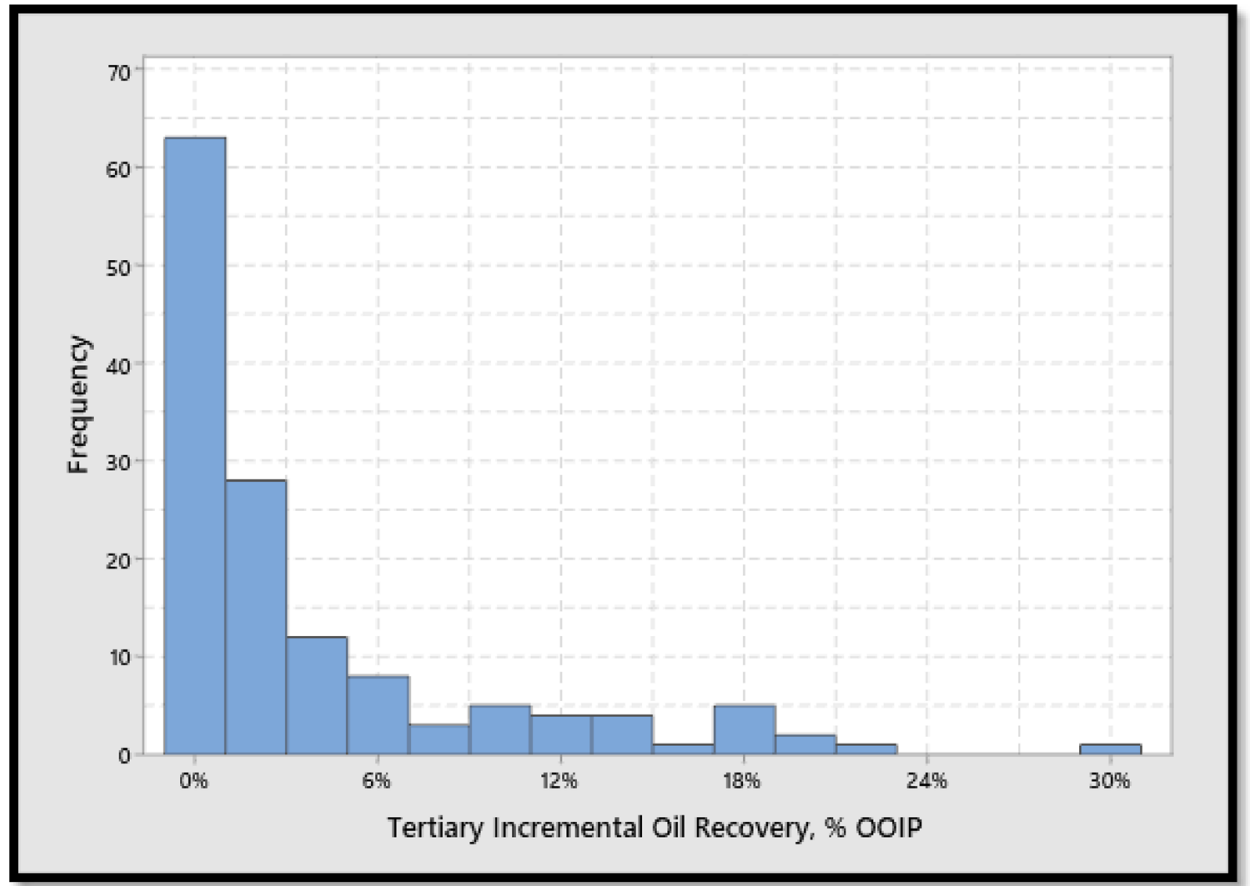

d Histogram of tertiary incremental oil recovery

obtains the same oil recovery in the secondary and tertiary recovery stages, but the oil rate in the secondary recovery stage is faster than in the tertiary recovery stage (accelerated recovery has occurred in the secondary recovery stage.

\section{Effect of water composition}

The significance of $\mathrm{SO}_{4}{ }^{2-}, \mathrm{Ca}^{2+}, \mathrm{Na}^{+}$and $\mathrm{Mg}^{+2}$ concentration during the application of the LSWF in the carbonate reservoirs was suggested by Austad et al. (2005), Zhang et al. (2006), Strand et al. (2008), Romanuka et al. (2012),
Bazhanova and Pourafshary (2020), and others. They suggested that the MIE is the mechanism of the wettability alteration in the carbonate reservoirs. The MIE mechanism is attributed to the adsorption of potential anions/cations such as $\mathrm{SO}^{2-}, \mathrm{Ca}^{2+}$ and/or $\mathrm{Mg}^{2+}$ onto the rock surface. Adsorption of the $\mathrm{SO}_{4}{ }^{2-}$ anions decreases the positive charge density on the rock surface. This behavior minimizes the electrostatic repulsive force and causes the $\mathrm{Ca}^{2+}$ and $\mathrm{Mg}^{2+}$ cations' co-adsorption on the rock surface. The reaction of the $\mathrm{Ca}^{2+}$ cations with the carboxylic acid groups results in breaking the attractive interactions between the oil and the 
Table 2 Flooding devices and measurement methods of the previous experimental studies

\begin{tabular}{|c|c|c|c|c|c|c|c|c|}
\hline \multirow[t]{2}{*}{ References } & \multicolumn{3}{|l|}{ Test type } & \multicolumn{5}{|c|}{ Wettability indication methods } \\
\hline & Core flooding & $\begin{array}{l}\text { Spontaneous } \\
\text { imbibition }\end{array}$ & Centrifuge & $\mathrm{pH}$ & IFT & Contact angle & Zeta potential & Amott index \\
\hline AlQuraishi et al. (2015) & $\sqrt{ }$ & & & & $\sqrt{ }$ & $\sqrt{ }$ & & \\
\hline Al Hamad et al. (2017) & $\sqrt{ }$ & $\sqrt{ }$ & & & $\sqrt{ }$ & $\sqrt{ }$ & & \\
\hline Tetteh et al. (2017) & $\sqrt{ }$ & & & & $\sqrt{ }$ & & & $\sqrt{ }$ \\
\hline Yousef et al. (2010) & $\sqrt{ }$ & & & & $\sqrt{ }$ & $\sqrt{ }$ & & \\
\hline Sari et al. (2017) & $\sqrt{ }$ & & & & $\sqrt{ }$ & $\sqrt{ }$ & $\sqrt{ }$ & \\
\hline Austad et al. (2012) & $\sqrt{ }$ & $\sqrt{ }$ & & & & & & \\
\hline Zahid et al. (2012) & $\sqrt{ }$ & & & & & & & \\
\hline Uetani et al. (2019) & & $\sqrt{ }$ & & & & & & \\
\hline Hamouda and Maevskiy (2014) & $\sqrt{ }$ & & & $\sqrt{ }$ & & & & \\
\hline Ali et al. (2012) & $\sqrt{ }$ & & & & $\sqrt{ }$ & $\sqrt{ }$ & $\sqrt{ }$ & \\
\hline Romanuka et al. (2012) & & $\sqrt{ }$ & & & & & & \\
\hline Gandomkar and Rahimpour. (2015) & $\sqrt{ }$ & & & $\sqrt{ }$ & & & & \\
\hline Aksulu et al. (2012) & & $\sqrt{ }$ & & & & & & \\
\hline Almeida et al. (2019) & & & $\sqrt{ }$ & & & & & \\
\hline Camargo et al. (2019) & $\sqrt{ }$ & & & & & & & \\
\hline Masalmeh et al. (2019) & $\sqrt{ }$ & & & & & & & \\
\hline Bazhanova and Pourafshary (2020) & & $\sqrt{ }$ & & $\sqrt{ }$ & & $\sqrt{ }$ & & \\
\hline Abdeli and Seiden (2018) & $\sqrt{ }$ & & & & & $\sqrt{ }$ & & \\
\hline Ghandi et al. (2019) & & $\sqrt{ }$ & & & $\sqrt{ }$ & $\sqrt{ }$ & & \\
\hline Zekri et al. (2019) & $\sqrt{ }$ & & & $\sqrt{ }$ & & & & \\
\hline Hosseini et al. (2020) & $\sqrt{ }$ & & & $\sqrt{ }$ & $\sqrt{ }$ & $\sqrt{ }$ & & \\
\hline Abdelhamid and Elnaggar. (2017) & $\sqrt{ }$ & & & & & & & \\
\hline Al Harrasi et al. (2012) & $\sqrt{ }$ & $v$ & & & & & & \\
\hline
\end{tabular}

rock interface, which changes the rock surface behavior to be more water wet. Gopani et al. (2021) documented that the effect of the $\mathrm{Mg}^{2+}$ cations on the oil recovery during the application of the LSWF in the carbonate rock is less than that of the $\mathrm{Ca}^{2+}$ cations due to the low solubility of $\mathrm{MgSO}_{4}$ in the brine at ambient conditions. In another study, Olayiwola and Dejam (2021) demonstrated that the concentrations of $\mathrm{Ca}^{2+}, \mathrm{SO}_{4}{ }^{2-}, \mathrm{Mg}^{2+}$ ions react with the carboxylic component oil and cause a great effect on the wettability of carbonate reservoirs.

Yousef et al. (2011), Shariatpanahi et al. (2011a), and others hypothesized that injection of sea water containing a high amount of $\mathrm{SO}_{4}{ }^{2-}$ anions could alter the wettability to be more water wet and increase oil recovery. The incremental oil recovery was documented in the tertiary recovery stage due to high sulfate concentration on chalks cores and limestone cores (Zhang and Austad 2005; Hognesen et al. 2005; Al-Attar et al. 2013; and Zekri et al. 2019). They showed that reducing the sea water's salinity slightly affected the carbonate rock wettability and could not increase oil recovery. They documented that increasing the sulfate concentration beyond some optimum concentration of 47 ppm can cause a negative effect on the flooding process. In another study, Zhang et al. (2006) documented that increasing the concentration of $\mathrm{SO}^{-2}$ anions and decreasing $\mathrm{NaCl}$ concentration in the injected water cause a change in the wettability and improve the oil recovery from the carbonate reservoirs.

On the other hand, Abdeli and Seiden (2018) observed that the presence of the $\mathrm{Mg}^{2+}$ cations in the injecting brine would affect the ultimate oil recovery much more than the $\mathrm{Ca}^{2+}$ cations. They showed that the oil recovery factor was not affected significantly by removing the $\mathrm{Ca}^{2+}$ cation from the injection solution. In addition, Zekri et al. (2019) reported an insignificant effect of the sulfate in the injected water. They concluded that adding sulfate into the water would increase the process's overall cost without improving oil recovery effectiveness.

Furthermore, Al Hamad et al. (2017) studied the iodide effects in the water injection within the carbonate rocks. They clarified that sodium iodide has a tendency to alter the rock wettability to be stronger water wet conditions. In addition, they documented an increase of 3-12\% incremental oil recovery using dolomitic core plugs by increasing $\mathrm{NaI}$ from 0 to $1000 \mathrm{ppm}$ in the injected water and with no change in the other minerals. Moreover, they reported that using limestone core plugs gave an increase of $0-17 \%$ incremental oil 

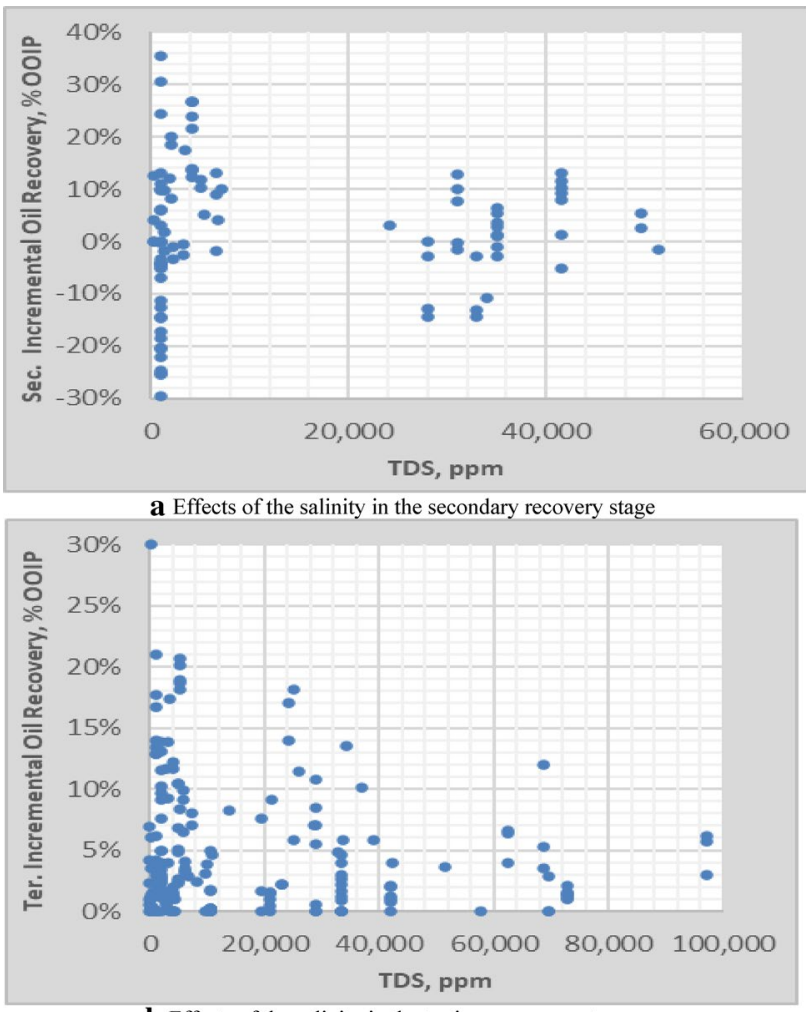

b Effects of the salinity in the tertiary recovery stage

Fig. 3 Incremental oil recovery versus the injected water salinity in the secondary and tertiary recovery stages

recovery in the tertiary recovery stage by changing the sea water (the sea water was diluted to $1000 \mathrm{ppm}$ saline water, including $1000 \mathrm{ppm}$ of NaI minerals only). In another study, Hosseini et al. (2020) found that the $\mathrm{H}_{2} \mathrm{PO}_{4}{ }^{-}$anions can act as a neutralizing agent to reduce the surface charge in the carbonated reservoirs.

Figure 4 shows the relation between the $\mathrm{SO}_{4}{ }^{2-}, \mathrm{Ca}^{2+}$, $\mathrm{Na}^{+}, \mathrm{Mg}^{2+}$, and $\mathrm{K}^{+}$contents of the injected low saline water versus the incremental oil recovery in the secondary recovery stage using core plugs of carbonate rocks. There is no clear relationship between incremental oil recovery and water composition. The highest and lowest oil recovery values were documented with each mineral's presence and absence in the injected water. In addition, the LSWF showed oil recovery up to $25 \%$ with no sulfates in the injected water.

In the collected data experiments, when the effects of the injected water minerals were studied during the secondary recovery stage, two experiments were usually carried out using either (1) twin core plugs or (2) the same core plug after cleaning and repeating all the experimental procedure. The two experiments were usually carried out using two different salinities and compositions (HS and LS). Figure 5 shows the impacts of the difference in the concentration of the injected water minerals on the oil recovery during the secondary recovery stage. The figure's negative values mean that the concentration of the LS water components is lower than that in the HS water. However, the positive values mean that the LS water components' concentration is higher than that in the HS water. Figure 5a shows that a decrease in the $\left(\mathrm{Na}^{+}+\mathrm{K}^{+}\right)$cations concentration leads to an incremental oil recovery in most of the core plugs. However, an increase and decrease in the incremental oil recovery were reported in the experiments, which were conducted without changing the concentration of $\left(\mathrm{Na}^{+}+\mathrm{K}^{+}\right)$cations. The same observation was documented during the decrease in the $\left(\mathrm{SO}_{4}{ }^{2-}+\mathrm{Ca}^{2+}+\mathrm{Mg}^{2+}\right)$ concentrations, as shown in Fig. 5 b. Either a decrease or increase in the concentration of these components in the brine water showed an incremental oil recovery.

Figure $5 c, d$ show that decreasing the concentration of the $\left(\mathrm{Ca}^{2+}+\mathrm{Mg}^{2+}\right)$ cations may be important than reducing the concentration of the $\mathrm{SO}_{4}{ }^{2-}$ anions in the injected water. Most of the core plugs showed additional incremental oil recovery with decreasing the concentration of $\left(\mathrm{Ca}^{2+}+\mathrm{Mg}^{2+}\right)$ cations, while the change in the concentration of the sulfate did not reveal a clear effect with oil recovery.

Figure 5e showed that decreasing the divalent and monovalent concentration led to additional incremental oil

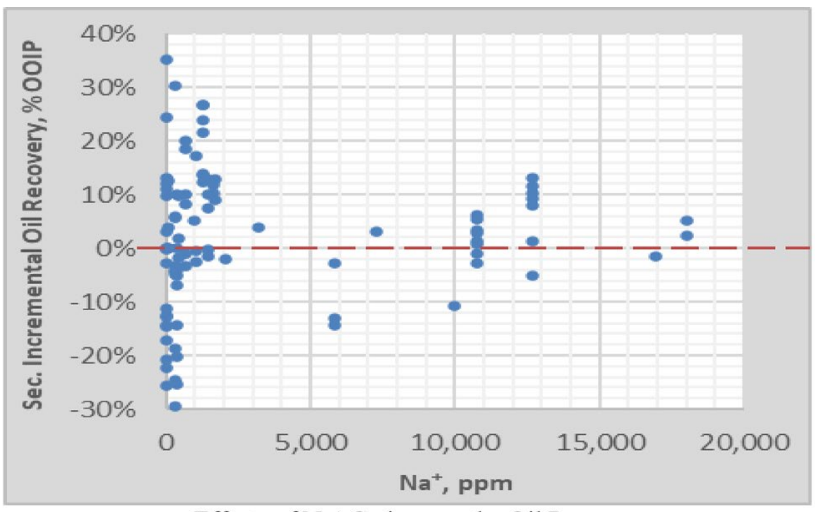

a Effects of $\mathrm{Na}^{+}$Cations on the Oil Recovery

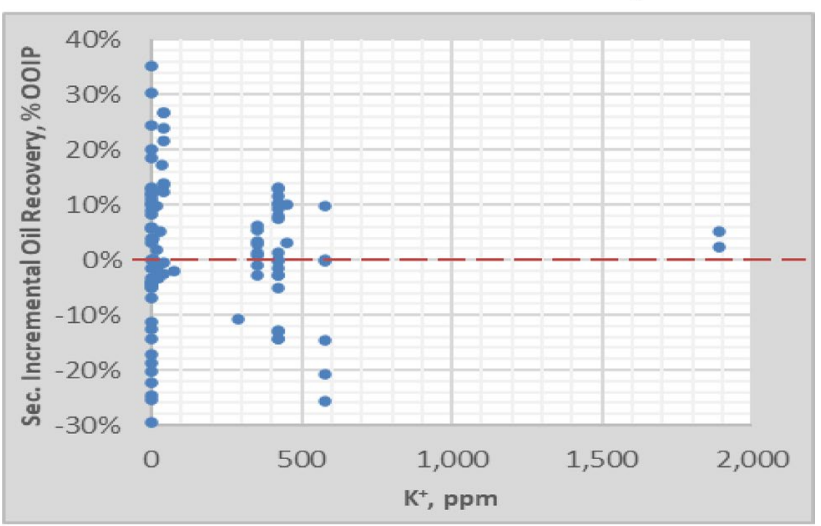

b Effects of $\mathrm{K}^{+}$Cations on the Oil Recovery

Fig. 4 Effects of the concentration of the injected water minerals on the oil recovery during the secondary recovery stage 


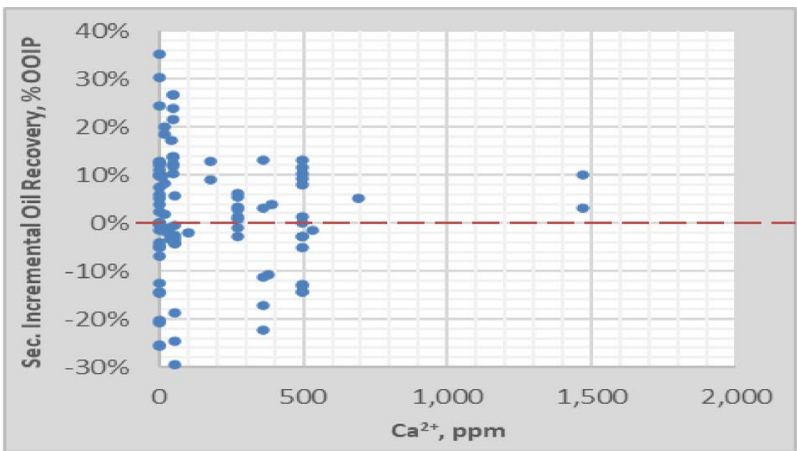

C Effects of $\mathrm{Ca}^{2+}$ cations on the oil recovery

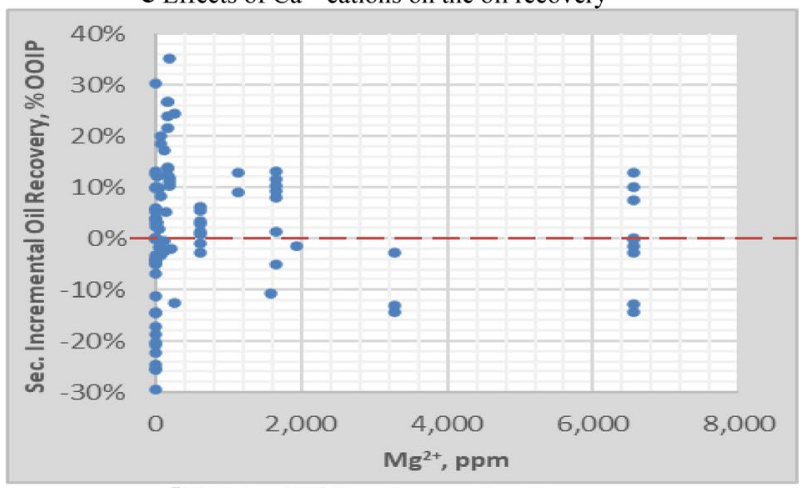

d Effects of $\mathrm{Mg}^{2+}$ cations on the oil recovery

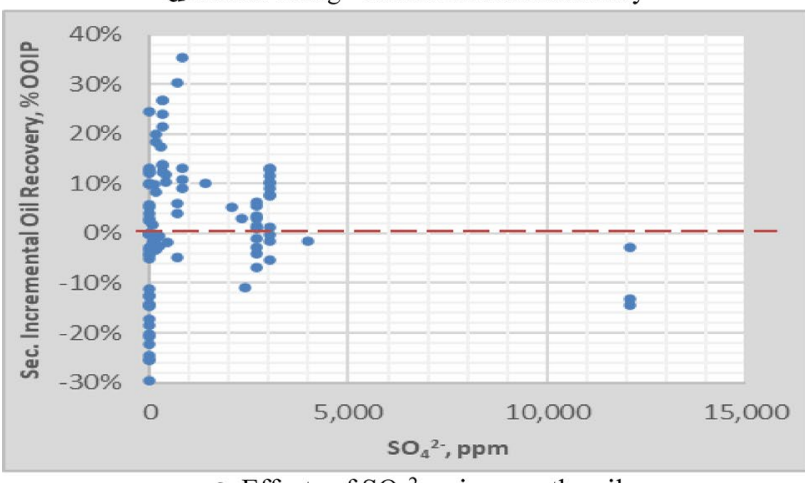

e Effects of $\mathrm{SO}_{4}{ }^{2-}$ anions on the oil recovery

Fig. 4 (continued)

recovery in most of the studies. However, the decrease of the divalent relative to the monovalent is better and gives better incremental oil recovery compared to the reverse cases, as shown in Fig. 5f. Abdeli and Seiden (2018) documented that the ratio of $\left[\mathrm{SO}_{4}{ }^{2-}\right] /\left[\mathrm{Mg}^{2+}\right]$ concentrations in the injected water could be a controlling parameter in the process of changing the carbonate rock wettability. However, neither the ratio of $\left[\mathrm{SO}_{4}{ }^{2-}\right] /\left[\mathrm{Mg}^{2+}\right]$ nor $\left[\mathrm{SO}^{2-}\right] /\left[\mathrm{Ca}^{2+}+\mathrm{Mg}^{2+}\right]$ concentrations in the injected water revealed any clear relationship with the incremental oil recovery in the secondary recovery stage, as shown in Fig. $5 \mathrm{~g}$, h, respectively.

The same observations for the effects of the water minerals on the oil recovery during the tertiary WF are shown in Figs. 6 and 7. Figure 6 shows the relation between the additional oil recovery from carbonate core plugs in the tertiary recovery stage versus the concentrations of the $\mathrm{SO}_{4}{ }^{2-}, \mathrm{Ca}^{2+}$, $\mathrm{Na}^{+}, \mathrm{Mg}^{2+}$, and $\mathrm{K}^{+}$in the injected low saline water. It is obviously clear that there is no clear relationship between the incremental oil recovery and the concentrations of the minerals in the injected water. The highest and lowest oil recovery values were documented with each mineral's presence and absence in the injected water. In addition, more oil recovery of up to $30 \%$ was observed with the absence of sulfates in the injected water.

In the collected data experiments, when the effects of the injected water minerals were studied during the tertiary recovery stage, each core plug was initially flooded with water (secondary recovery stage). The same core plug was then flooded with water of different salinity and composition at the same conditions in the tertiary recovery stage. The water in the tertiary stage may be HS or LS water. The additional oil recovery due to the change of the injected water salinity was calculated and reported.

Figure 7 shows the difference between the water minerals in the tertiary recovery stage. The negative values mean that the concentration of the secondary recovery stage components is lower than that in the tertiary recovery stage. However, the positive values mean that the concentration of the secondary recovery stage components is higher than that in the tertiary recovery stage. Figure $7 \mathrm{a}$ illustrates that a decrease in the $\left(\mathrm{Na}^{+}+\mathrm{K}^{+}\right)$cations concentration leads to an incremental oil recovery in most of the core plugs. However, some of the experiments reported an incremental oil recovery without changing the concentration of $\left(\mathrm{Na}^{+}+\mathrm{K}^{+}\right)$ cations. The same observation was documented during the decrease in the concentration $\left(\mathrm{SO}_{4}^{2-}+\mathrm{Ca}^{2+}+\mathrm{Mg}^{2+}\right)$, as shown in Fig. 7b. Figure 7c, d demonstrate that the decrease in the concentration of the $\left(\mathrm{Ca}^{2+}+\mathrm{Mg}^{2+}\right)$ cations or the $\mathrm{SO}_{4}{ }^{2-}$ anions in the injected water can positively affect the tertiary WF's performance without any clear and consistent relation. However, Fig. 7e shows that the decrease in divalent and monovalent concentration leads to incremental oil recovery in most studies. However, the decrease of the divalent relative to the monovalent is better and gives better incremental oil recovery compared to the reverse cases, as shown in Fig. 7f. Neither the ratio of $\left[\mathrm{SO}_{4}{ }^{2-}\right] /\left[\mathrm{Mg}^{2+}\right]$ nor $\left[\mathrm{SO}^{2-}\right] /\left[\mathrm{Ca}^{2+}+\mathrm{Mg}^{2+}\right]$ concentrations in the injected water revealed any clear relationship with the incremental oil recovery in the tertiary recovery stage as shown in Fig. $7 \mathrm{~g}$, $h$, respectively.

The results of the previous studies indicate that the value of the water salinity has no effect on the oil recovery during the WF, but the composition of the injected water is the key parameter for the waterflooding in the carbonate reservoirs. In addition, defining a unique composition for all types of rocks is difficult. Moreover, decreasing the divalent cations $\mathrm{Ca}^{2+}$ and $\mathrm{Mg}^{2+}$ may increase the oil recovery in the secondary recovery stage. Moreover, it should be highlighted that

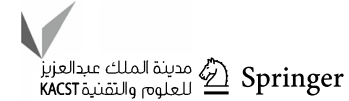


Fig. 5 Secondary incremental oil recover versus the difference in the concentration of the injected water minerals (Low salinity-High salinity)

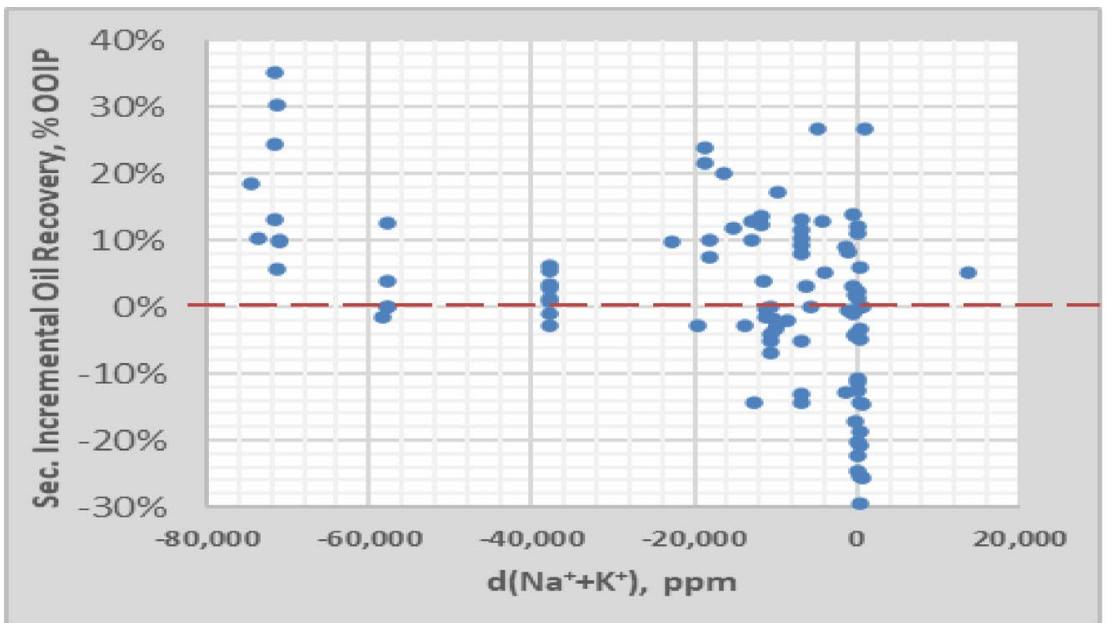

a Effects of the difference in concentration of $\left(\mathrm{Na}^{+}+\mathrm{K}^{+}\right)$on the oil recovery

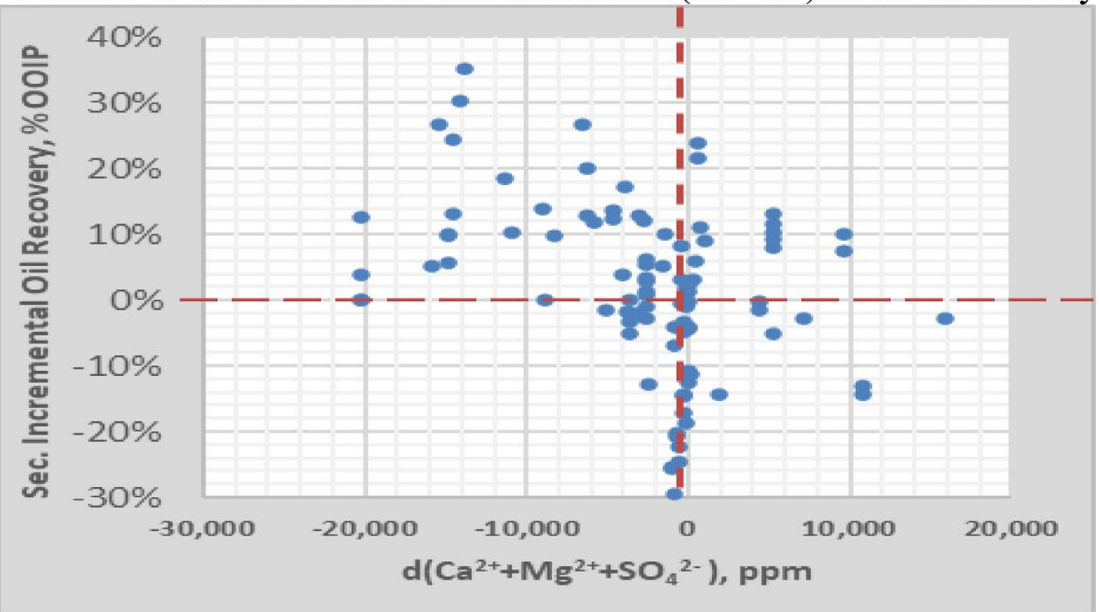

b Effects of the difference in concentration of $\left(\mathrm{Ca}^{2+}+\mathrm{Mg}^{2+}+\mathrm{SO}_{4}{ }^{2-}\right)$ on the oil recovery

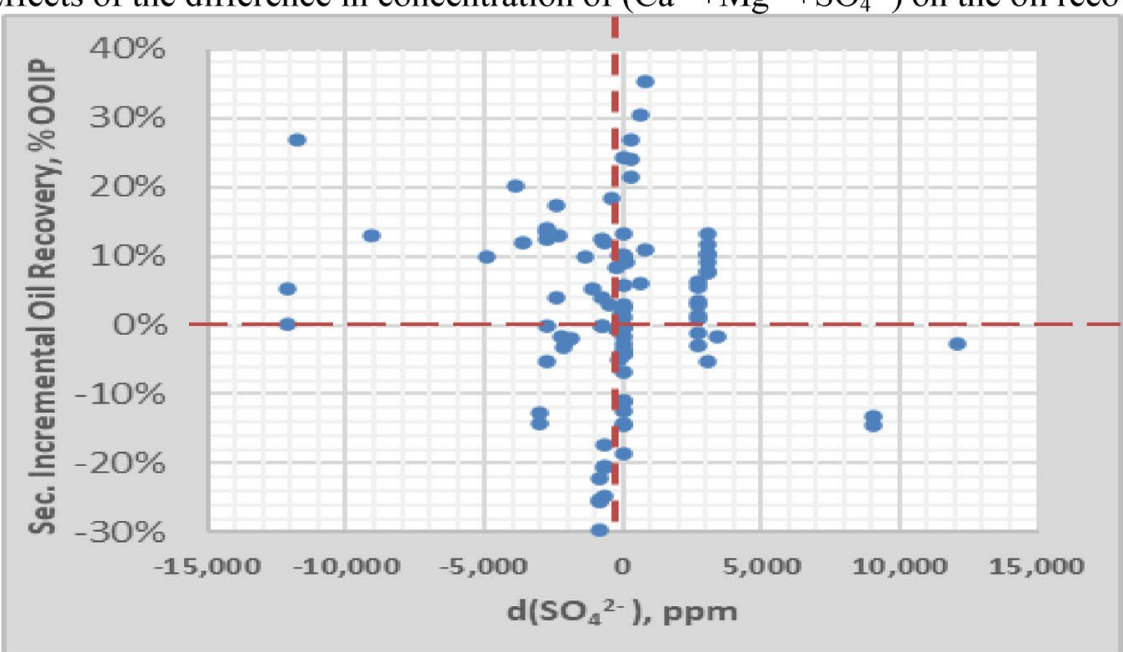

c Effects of the difference in concentration of $\left(\mathrm{SO}_{4}{ }^{2-}\right)$ on the oil recovery increasing the sulfate concentration in the injected water may increase the project's cost. Furthermore, it was clear that the sodium iodide (NaI) role has not been sufficiently studied and needs further investigation. Also, it is obviously clear that experimental work for each specific reservoir is necessary to determine the optimum salinity before the application of any waterflooding project (it is a specific application for a specific reservoir). 
Fig. 5 (continued)

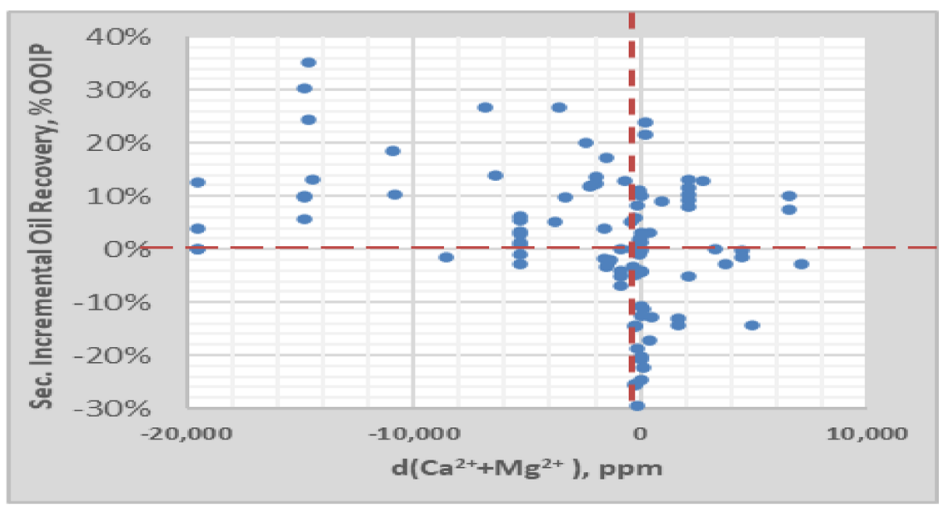

d Effects of the difference in concentration of $\left(\mathrm{Ca}^{2+}+\mathrm{Mg}^{2+}\right)$ on the oil recovery

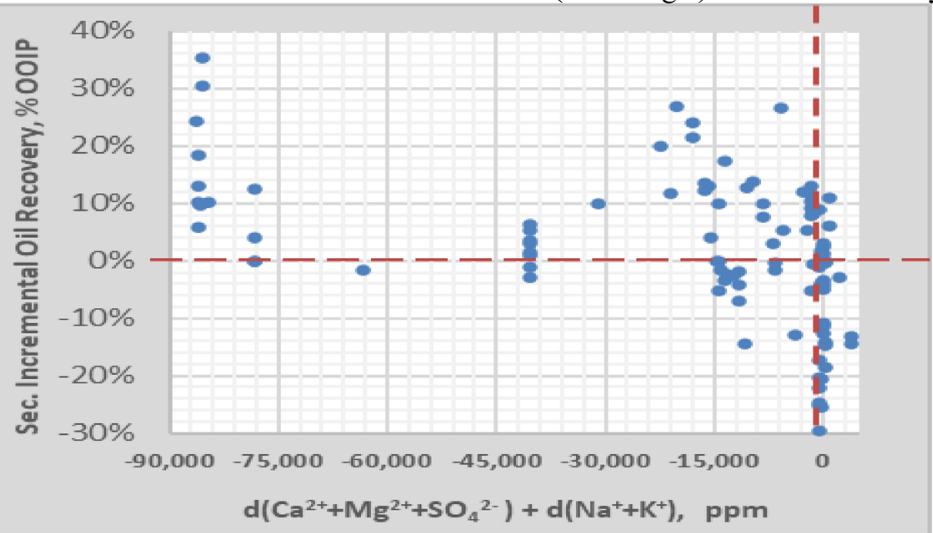

e Effects of the difference in concentration of $\mathrm{d}\left(\mathrm{Ca}^{2+}+\mathrm{Mg}^{2+}+\mathrm{SO}_{4}{ }^{2-}\right)+\mathrm{d}\left(\mathrm{Na}^{+}+\mathrm{K}^{+}\right)$on the oil recovery

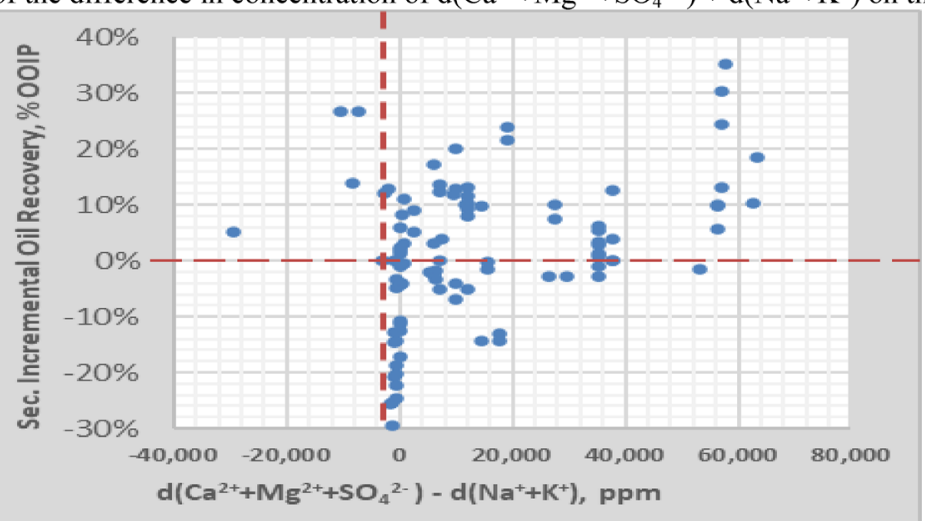

f Effects of the difference in concentration of $\mathrm{d}\left(\mathrm{Ca}^{2+}+\mathrm{Mg}^{2+}+\mathrm{SO}_{4}{ }^{2-}\right)-\mathrm{d}\left(\mathrm{Na}^{+}+\mathrm{K}^{+}\right)$on the oil recovery

\section{Effect of permeability and rock composition}

Zoshchenko et al. (2019) showed that spontaneous imbibition of LSWF with a total salinity of $\approx 5 \mathrm{~g} / \mathrm{l}$ could increase the recovery factor up to $4 \%$ and give additional recovery for core plugs with permeability less than $100 \mathrm{md}$. However, no direct relationship between the permeability and the incremental oil recovery was reported in the collected data, as shown in Fig. 8a, b. Additional incremental oil recovery was observed in all ranges of permeability.
The effect of the anhydrite has been studied in the literature as an important key parameter for LSWF applications. Austad et al. (2012) and Fathi et al. (2010) suggested that dissolution of the anhydrite into $\mathrm{Ca}^{2+}$ and $\mathrm{SO}_{4}{ }^{2-}$ would generate in situ catalytic agent sulfate. This catalytic agent is required to release the carboxylic groups from the reservoir rock's surface.

Austad et al. (2012) and Fathi et al. (2010) did not observe any effect of applying the LSWF in chalk core plugs free of anhydrite. Austed et al. (2015) showed that the anhydrite 
Fig. 5 (continued)

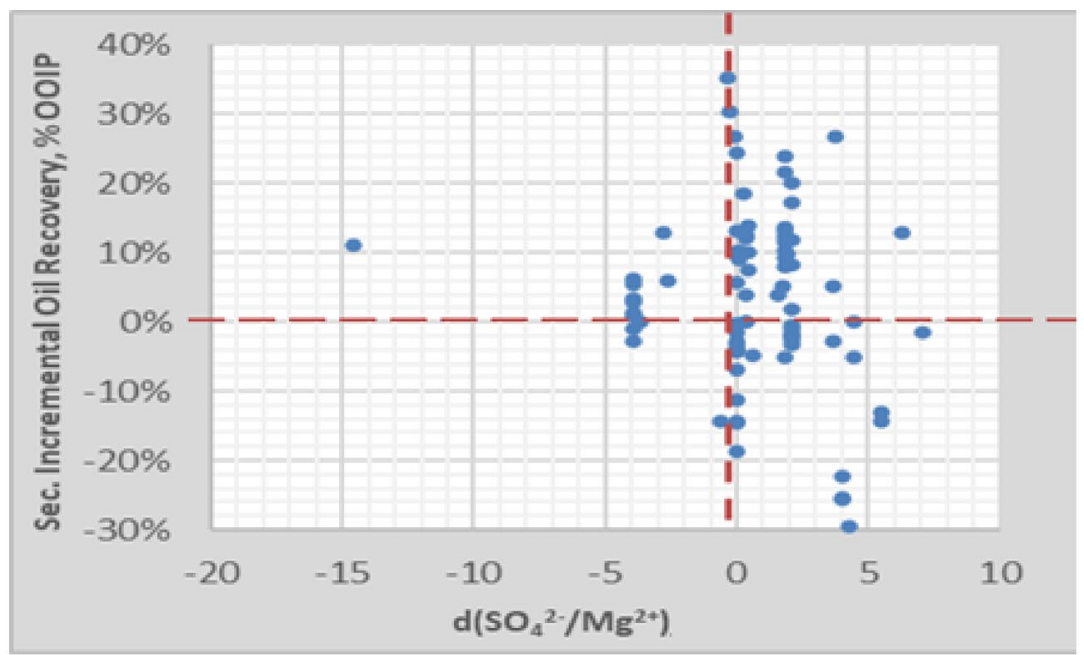

g Effects of the difference in concentration of $\mathrm{d}\left(\mathrm{SO}_{4}{ }^{2-} / \mathrm{Mg}^{2+}\right)$ on the oil recovery

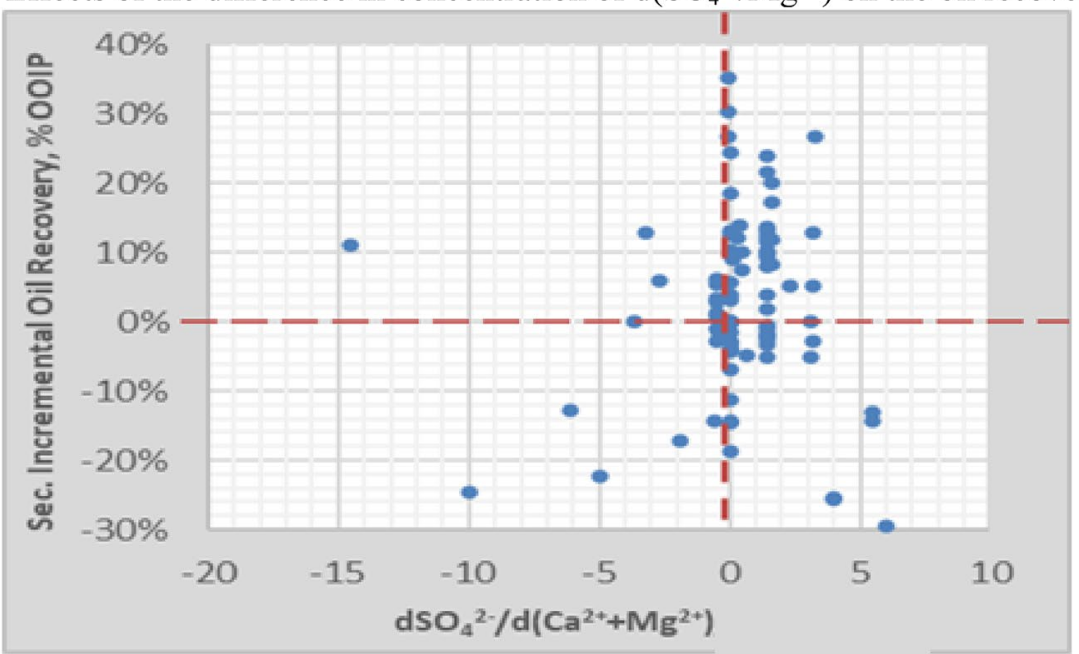

$\mathbf{h}$ Effects of the difference in concentration of $\mathrm{dSO}_{4}{ }^{2-} / \mathrm{d}\left(\mathrm{Ca}^{2+}+\mathrm{Mg}^{2+}\right)$ on the oil recovery

$\left(\mathrm{CaSO}_{4}\right)$ appears to be the main factor for observing the low salinity EOR effect in carbonate reservoirs. However, they showed that anhydrite's effect in the LSWF is still debated and needs further investigation. Aksulu et al. (2012) indicate that the seawater would act as an EOR fluid in the limestone reservoirs, but its potential is probably smaller than the sea water's effect in the chalk rocks.

On the other hand, Gandomkar and Rahimpour (2015) conducted various WF experiments using 12 core plugs containing $10 \%$ anhydrite. These experiments did not achieve any incremental oil recovery in the tertiary recovery stage. They concluded that the limestone reservoir with anhydrite may not be suitable for the applications of the LSWF in the tertiary recovery stage. Their experiments were performed at $60^{\circ} \mathrm{C}$. It should be highlighted that their experiments in the secondary recovery stage showed opposite results. The core plugs with $10 \%$ anhydrite showed 0 to $30 \%$ additional incremental oil recovery with HSWF and LSWF in the secondary recovery stage. Al Harrasi et al. (2012) and Hosseini et al. (2020) showed an incremental oil recovery of up to $20 \%$ using core plugs free of anhydrite with injected water free of sulfate. However, Uetani et al. (2019) achieved additional oil recovery in all the LSWF experiments regardless of the rock samples' anhydrite content. They reported that the anhydrite was not a mandatory mineral for the LSWF effect in the carbonate rock. In addition, the anhydrite dissolution was considered questionable as a key mechanism of the LSWF in the carbonate reservoirs. In another study, Jiang et al. (2014) did not observe any improvement in the oil recovery in their core flood experiments which were conducted using carbonate rock samples that contained anhydrite. 

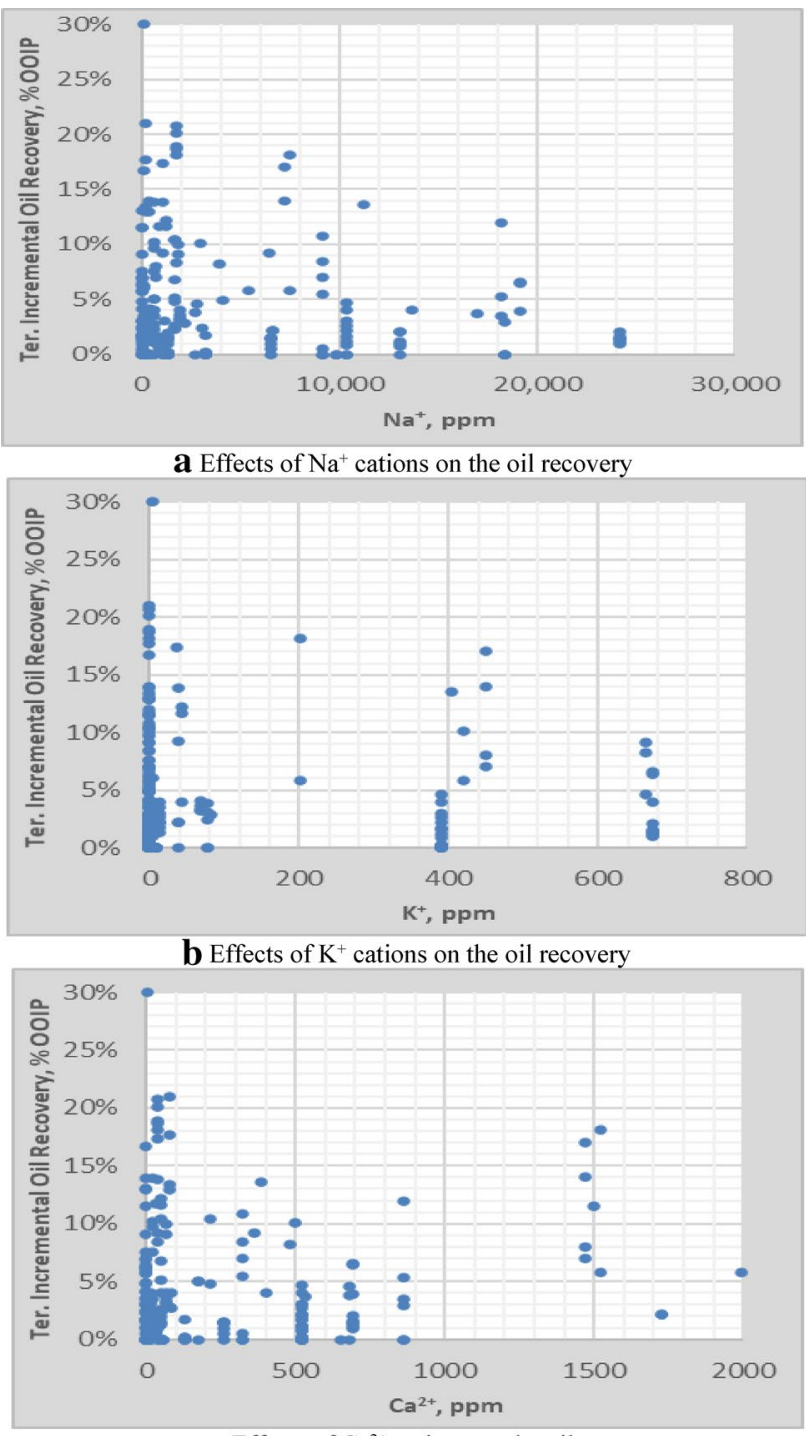

c Effects of $\mathrm{Ca}^{2+}$ cations on the oil recovery

Fig. 6 Effects of the concentration of the injected water minerals on the oil recovery during the tertiary recovery stage

Figure $9 \mathrm{a}-\mathrm{c}$ show the relation between the anhydrite, calcite, and dolomite concentration with the incremental oil recovery in the tertiary recovery stage. It should be highlighted that no clear relationship is observed between the rock minerals and the incremental oil recovery, as shown in Fig. 9. However, it is observed that increasing the concentration of the anhydrite may decrease the effectiveness of the LSWF in the tertiary recovery stage. It should be highlighted that the effect of anhydrite on the oil recovery in the secondary recovery stage was not plotted due to the unavailability of the data. The literature has few and limited experiments in
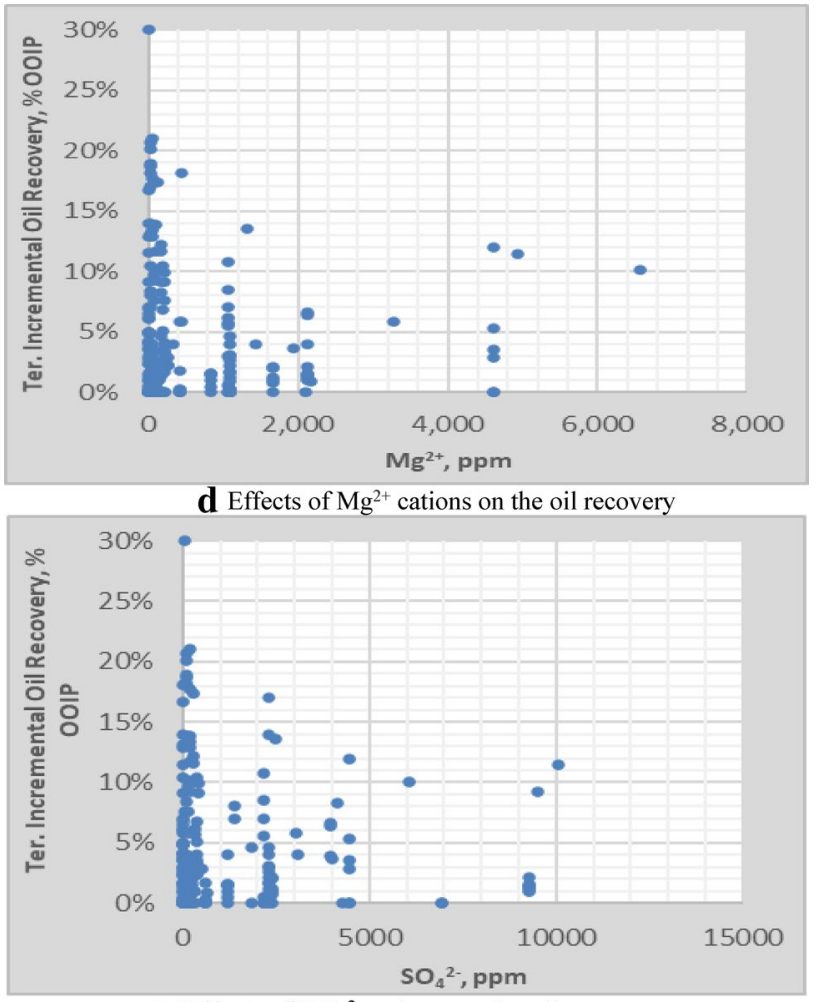

e Effects of $\mathrm{SO}_{4}{ }^{2-}$ anions on the oil recovery

Fig. 6 (continued)

the available database for core plugs with rock descriptions in the secondary recovery stage.

\section{Effect of oil composition}

Den Ouden et al. (2015), Austad et al. (2012), Al-Khafaji et al. (2017), and Sari et al. (2017) documented that the higher incremental oil recovery with the application of the WF in the carbonate reservoirs is expected with the presence of the higher acidity oil due to the higher concentration of the carboxylates. The more carboxylates can be adsorbed on the carbonate rock surface, and the rock becomes more oil-wet. Decreasing the salinity shifts the polarity of zeta potential at the fluid-rock interface; accordingly, the wettability is changed. Sari et al. (2017) showed that the LSWF incremental oil recovery in the tertiary recovery stage may be attributed to shifting the rock's wettability from strongly water wet to intermediate wettability. Uetani et al. (2020) reported insignificant additional oil recovery by the application of the tertiary LSWF in core plugs containing low acidity oil. They documented that repeating the experiments with high acidity oil showed incremental oil recovery up 
Fig. 7 Tertiary incremental oil recovery versus the difference in the concentration of the injected water minerals (Secondary-Tertiary)

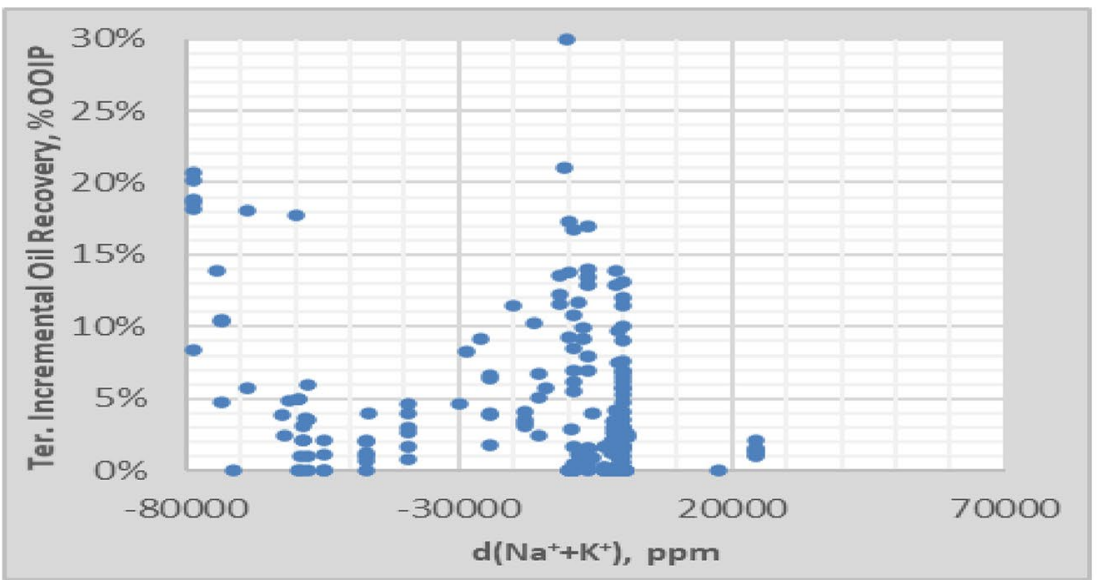

a Effects of the difference in concentration of $\mathrm{d}\left(\mathrm{Na}^{+}+\mathrm{K}^{+}\right)$on the oil recovery

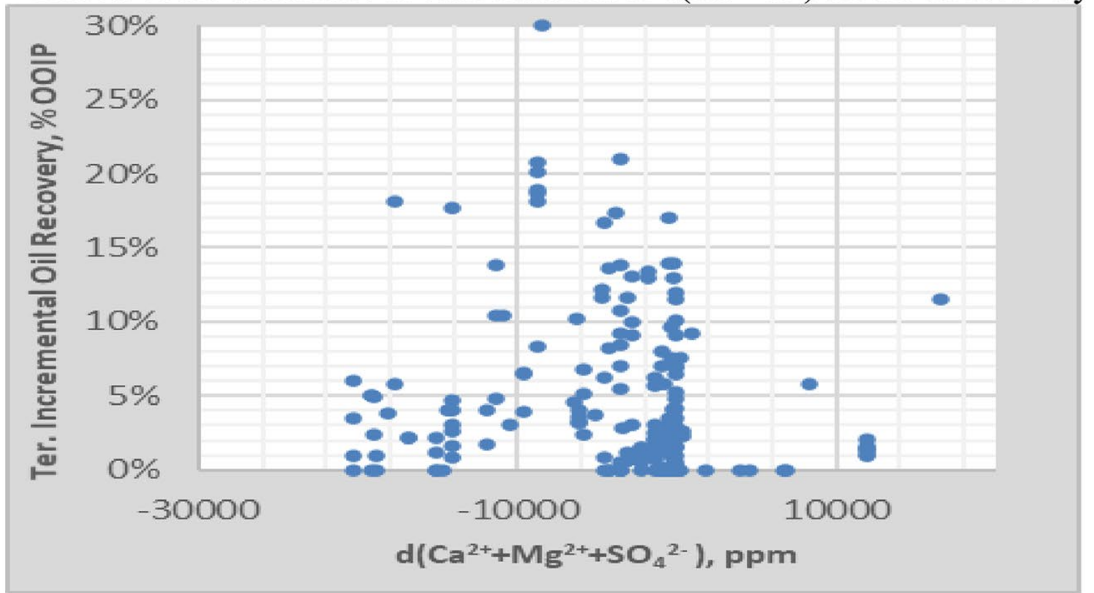

b Effects of the difference in concentration of $\mathrm{d}\left(\mathrm{Ca}^{2+}+\mathrm{Mg}^{2+}+\mathrm{SO}_{4}{ }^{2-}\right)$ on the oil recovery

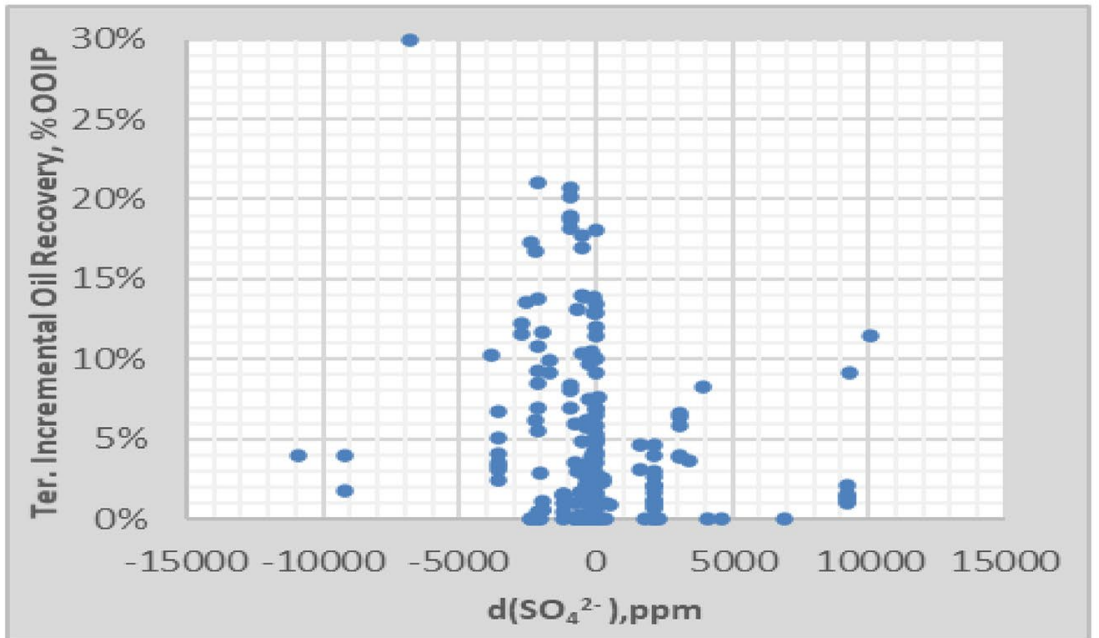

c Effects of the difference in concentration of $\mathrm{d}\left(\mathrm{SO}_{4}{ }^{2}\right.$ on the oil recovery to $23 \%$. Then, they concluded that the total acid number (TAN) and the recovery mode appear to be the major factors for successful LSWF applications in the carbonate system. Furthermore, Mozaffari et al. (2021) reported that the various acidic molecules in the crude oil, such as alkyl carboxylic acids, fused aromatic ring acids, alkylbenzene 
Fig. 7 (continued)

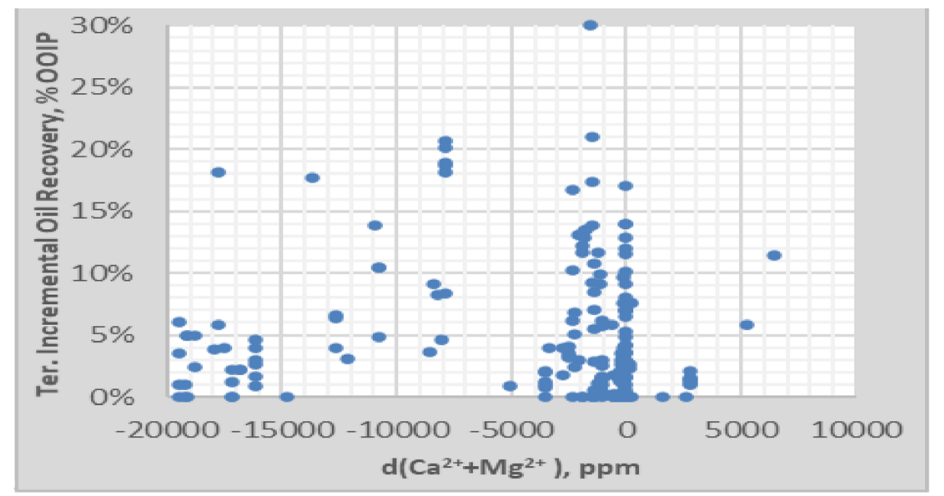

d Effects of the difference in concentration of $\mathrm{d}\left(\mathrm{Ca}^{2+}+\mathrm{Mg}^{2+}\right)$ on the oil recovery

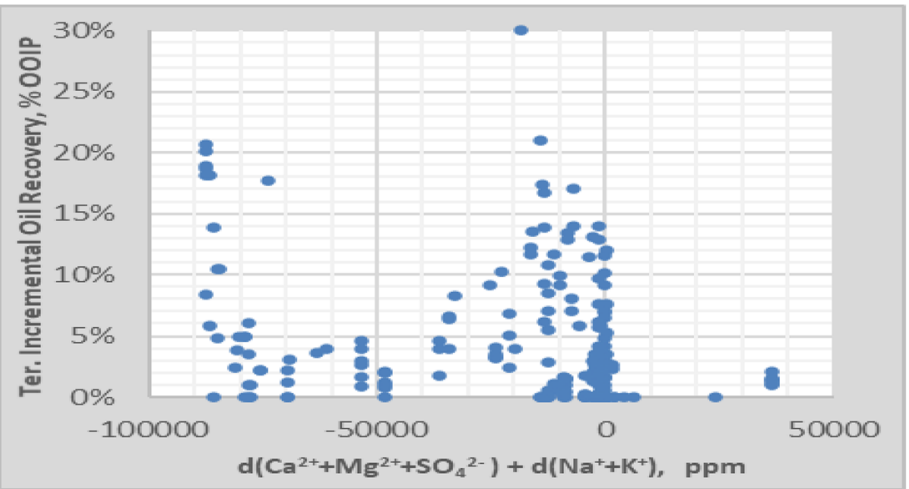

e Effects of the difference in concentration of $\mathrm{d}\left(\mathrm{Ca}^{2+}+\mathrm{Mg}^{2+}+\mathrm{SO}_{4}{ }^{2-}\right)+\mathrm{d}\left(\mathrm{Na}^{+}+\mathrm{K}^{+}\right)$on the oil recovery

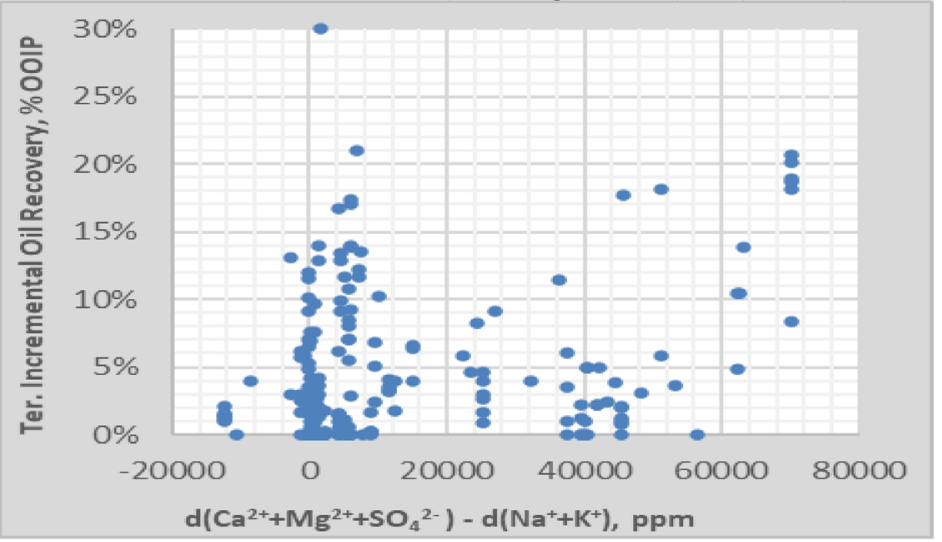

f Effects of the difference in concentration of $\mathrm{d}\left(\mathrm{Ca}^{2+}+\mathrm{Mg}^{2+}+\mathrm{SO}_{4}{ }^{2-}\right)-\mathrm{d}\left(\mathrm{Na}^{+}+\mathrm{K}^{+}\right)$on the oil recovery

carboxylic acids, and naphthenic acids, could reduce the IFT to a significant degree. Shechter et al. (2020) showed that changing the IFT of oil in water emulsion could alter the configuration of liquid crystals inside the oil droplet.

On the other hand, Al-Khafaji et al. (2017) and Masalmeh et al. (2019) indicated that the applications of the LSWF in the carbonate reservoir do not appear to be an effective technique with high acidity and heavy crude oil. However, Maskari et al. (2020) showed that the wettability change could occur in the carbonate reservoirs with crude oils containing lower polar components concentration.

Figure 10 shows the relation between the incremental oil recovery versus the total acid number and total base number in both secondary and tertiary recovery stages, respectively. It is clear that the number of available experiments which have TAN and TBN information in the database is limited. In addition, the available data indicate that there is no clear relationship between the incremental oil 
Fig. 7 (continued)

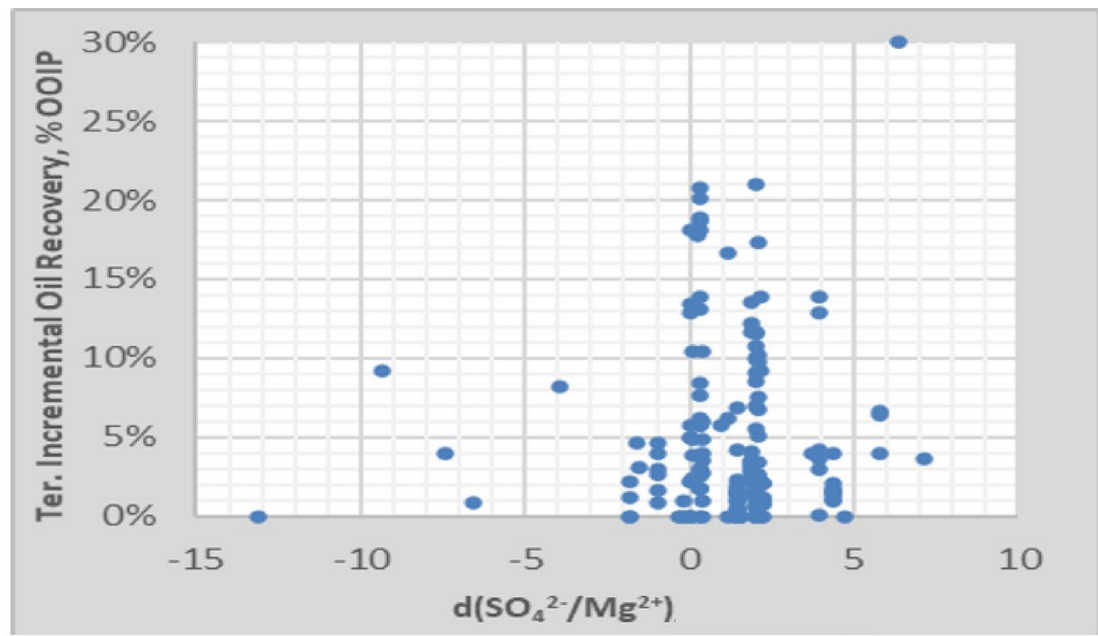

g Effects of the difference in concentration of $\mathrm{d}\left(\mathrm{SO}_{4}{ }^{2-} / \mathrm{Mg}^{2+}\right)$ on the oil recovery

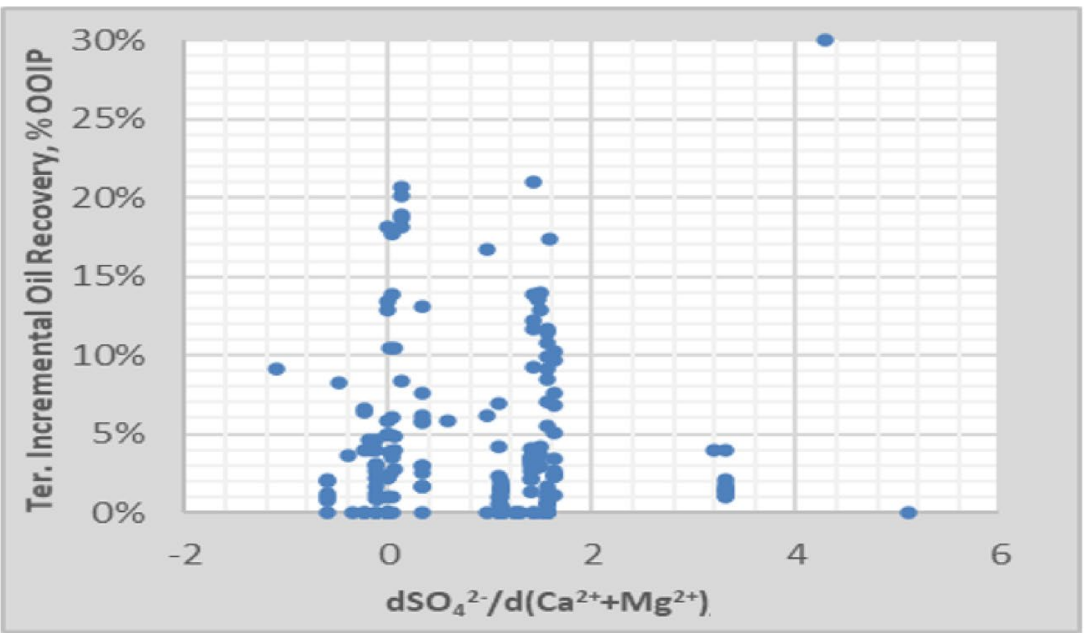

h Effects of the difference in concentration of $\mathrm{d} \mathrm{SO}_{4}{ }^{2-} / \mathrm{d}\left(\mathrm{Ca}^{2+}+\mathrm{Mg}^{2+}\right)$ on the oil recovery

recovery and the TAN or TBN in both secondary and tertiary recovery stages.

\section{Effect of temperature}

The LSWF effect was studied at different temperatures in the literature. Zahid et al. (2012) and Fathi et al. (2010) found that the LSWF could cause a dissolution of rock material and increase the oil recovery from carbonate core plugs at $90{ }^{\circ} \mathrm{C}$. In another study, Aksulu et al. (2012) found that the high temperatures $\left(T>130^{\circ} \mathrm{C}\right)$ can cause $\mathrm{Mg}^{2+}$ cations to substitute the $\mathrm{Ca}^{2+}$ cations on the carbonate surface; and accordingly, this behavior increases the oil recovery. In addition, Austad et al. (2012) documented that the reservoir temperature should be higher than $70-80{ }^{\circ} \mathrm{C}$ to obtain additional oil from the application of the LSWF in the carbonate rock. However, Shariatpanahi et al. (2011a), Zahid et al. (2012), and Mahani et al. (2018) reported that the application of the
LSWF is an effective process when it is applied in carbonate core plugs at ambient temperature.

Figure 11 shows the relation between the incremental oil recovery and several experiments' temperatures in both secondary and tertiary recovery stages. It is obviously clear that there is no distinct and direct relationship between the temperature and the incremental oil recovery in the secondary and tertiary recovery stages. It should be highlighted that incremental oil recovery values were documented with experiments of LSWF in carbonate rock during the tertiary recovery stage at a temperature higher than $60{ }^{\circ} \mathrm{C}$. However, in the secondary recovery stage, the incremental oil recovery values were observed at ambient temperature (Ghandi et al. 2019 and Abdelhamid and Elnaggar 2017). 


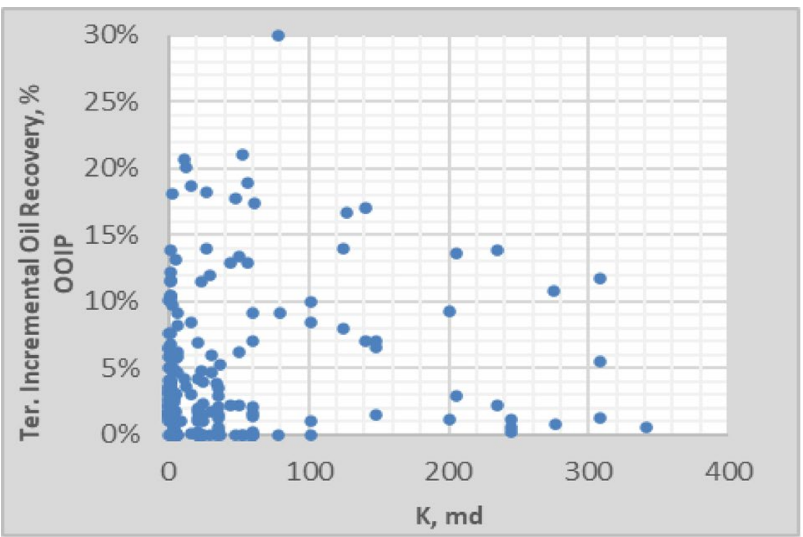

a Effects of the permeability in the tertiary recovery stage

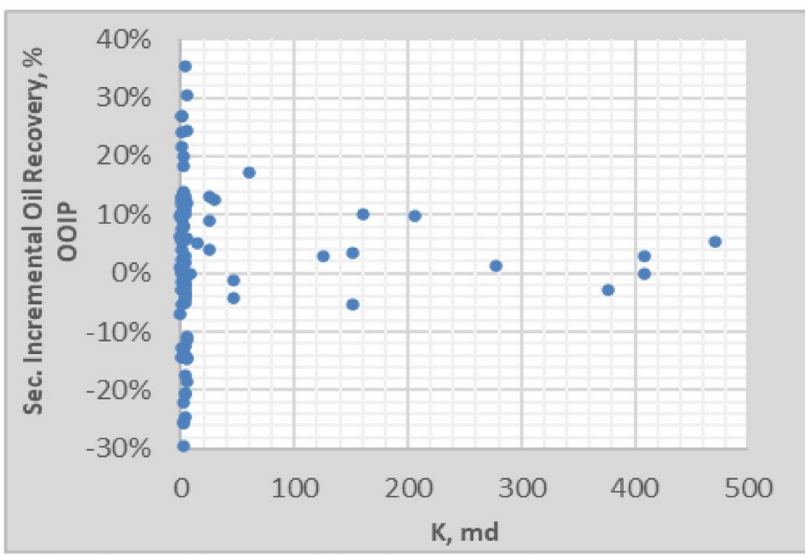

b Effects of the permeability in the secondary recovery stage

Fig. 8 Effects of the rock permeability on the oil recovery during the secondary and tertiary recovery stages

\section{Statistical analysis}

The previous discussion revealed many different parameters and mechanisms that influence LSWF applications in carbonate reservoirs. Therefore, statistical analysis was performed using Fractional factorial design (FFD) to identify the high effective parameters for incremental oil recovery in both secondary and tertiary recovery stages. Minitab software Version 19 was used to apply these statistical analyses (Minitab 2020).

The fractional factorial design is one of the most important statistical contributions to exploring the influence of many controllable factors on interest response (Gunst and Mason 2009). It is a commonly used experimental design method that can be used to enhance and simplify the studies. Plackett-Burman design is a popular type used for the FFD analysis. It is used to study the dependence of some measured quantity on several independent variables/factors (Plackett and Burman 1946). On the other hand, a Pareto chart is often a good tool for presenting the statistical analysis results and can be used to present the results of the Plackett-Burman design. The Pareto chart clarifies the
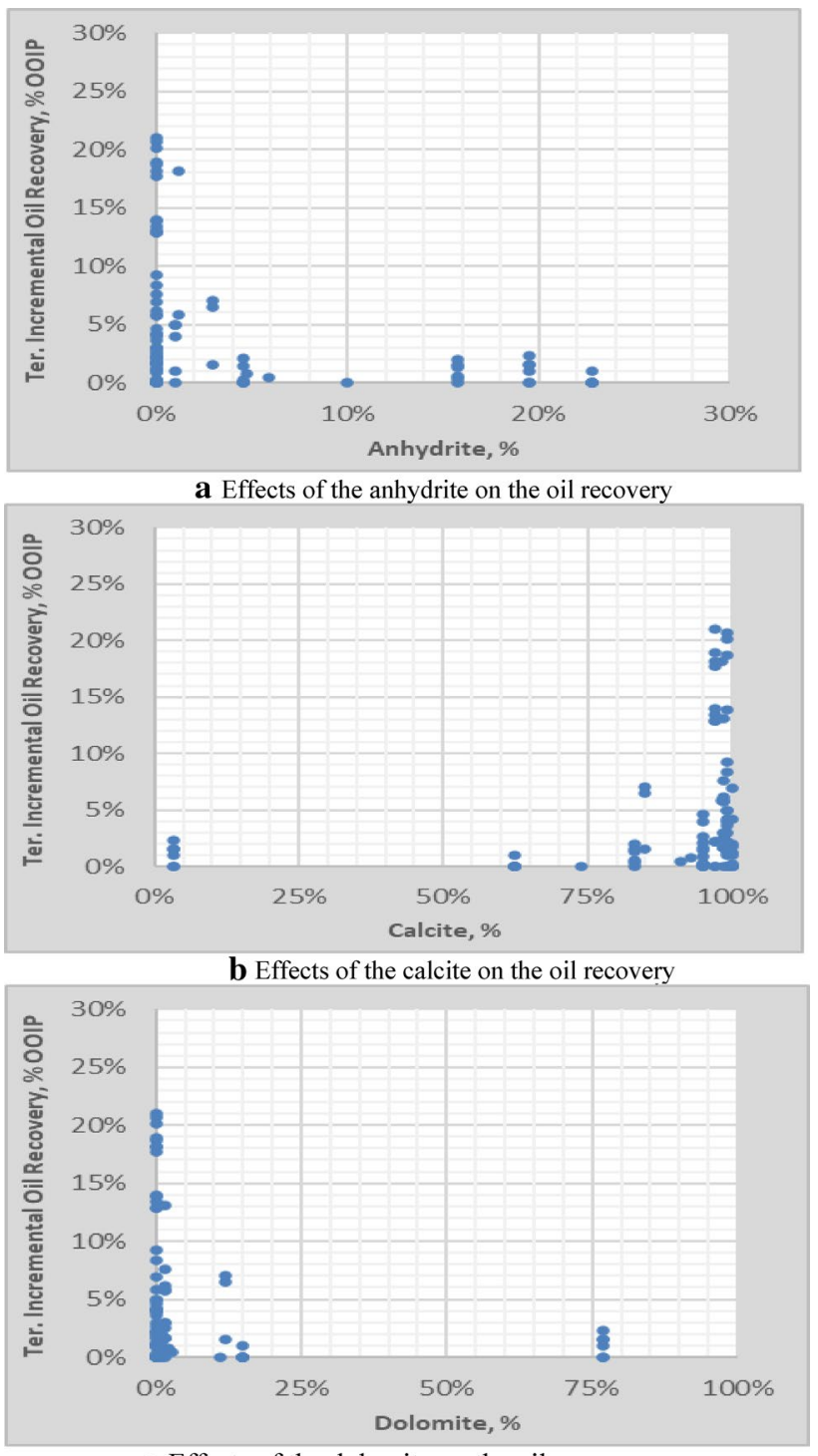

c Effects of the dolomite on the oil recovery

Fig. 9 Effects of the rock mineral types on the oil recovery during the tertiary recovery stage

absolute values of the standardized effects from the largest effect to the smallest effect, and the magnitude of each factor is clarified by a column (Arnold 2014).

This study used a two-level folded Plackett-Burman design to determine the high effective parameters on the incremental oil recovery in both secondary and tertiary recovery stages. The analysis was performed using rock minerals, HS water, and LS water properties. Several experiments in the database have a complete set of all parameters, while others did not have the rock's properties as a result that the statistical analysis was carried out twice. The first statistical analysis was performed using all data without considering the parameters of the rock properties. However, the second statistical analysis was carried out using the 
Fig. 10 Incremental oil versus oil acid and base numbers in the secondary and tertiary recovery stages

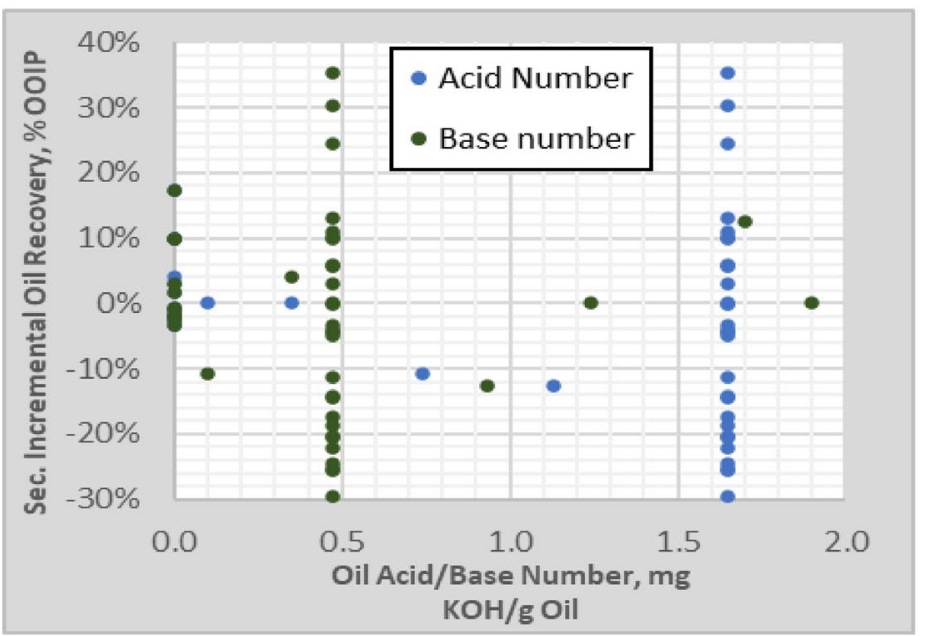

a Effects of the oil acid and base numbers on the oil recovery during the secondary recovery stage

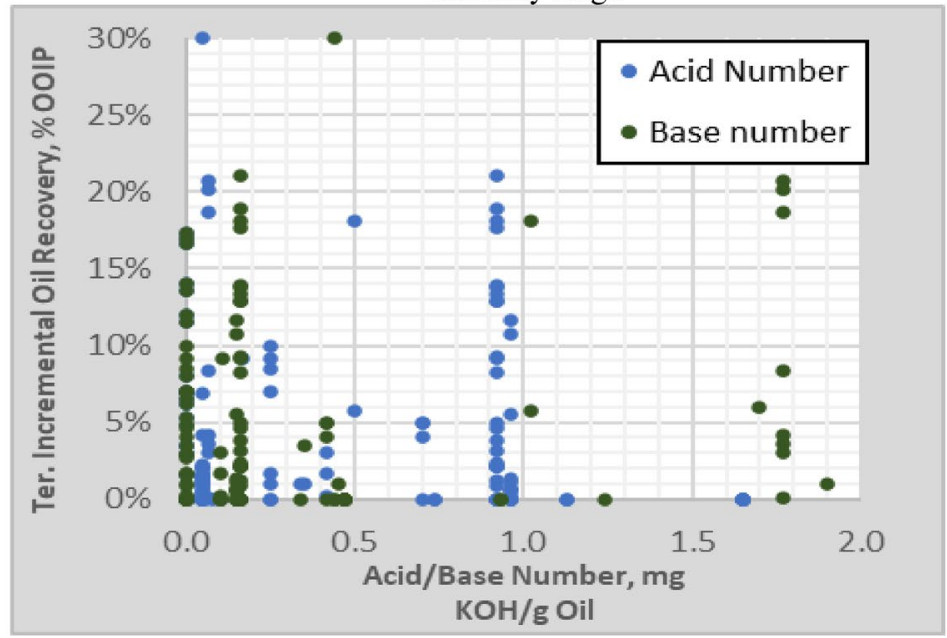

b Effects of the oil acid and base number on the oil recovery during the tertiary recovery stage experiments, which included rock properties. Furthermore, the analysis was performed for both secondary and tertiary recovery stages individually. Accordingly, four statistical analyses were carried out to identify the parameters which have the most influence on the LSWF.

Figure 12 shows the statistical analysis for the results of the secondary recovery stage experiments when using all data sets without including the rock minerals in the regression. It is clear that the greatest influence parameters in the secondary WF are the minerals concentrations of the HS injected water $\left(\mathrm{Mg}^{2+}, \mathrm{Na}^{+}, \mathrm{K}^{+}\right.$, and $\left.\mathrm{Cl}^{-}\right)$. However, the effect of the temperature and the concentration of two water minerals $\left(\mathrm{Ca}^{+2}\right.$ and $\left.\mathrm{SO}_{4}{ }^{2-}\right)$ in the injected water was found to be moderate. In addition, the effects of the TDS and the concentrations of the other water minerals in the oil recovery appear to be minimal. It should be highlighted that the mineral description for the core samples in the secondary recovery stage is very limited to extract a solid conclusion and a general result. The statistical analysis results are matched with the previous discussion in the previous section of this work. The results reveal that adjusting the injected water minerals can lead to higher oil recovery of the secondary WF in the carbonate reservoir.

Figure 13a, b show the statistical analysis results for the application of the LSWF in the tertiary recovery stage without and with the rock minerals, respectively. It is obviously clear that the statistical analysis of the results of the tertiary recovery stage experiments without considering the rock minerals in the regression (Fig. 13a) indicates that the most dominant parameters in the LSWF applications in the carbonate reservoir are the rock permeability, the $\mathrm{HCO}_{3}{ }^{-}$concentration in the LS injected water, and the $\mathrm{SO}_{4}{ }^{2-}$ concentration in the HS injected water. When the rock minerals are taken into considerations during the statistical analysis for the results of the tertiary recovery stage experiments (Fig. 13b); the rock minerals and the concentrations of several minerals $\left(\mathrm{K}^{+}, \mathrm{Cl}^{-}, \mathrm{Ca}^{2+}, \mathrm{SO}_{4}{ }^{2-}, \mathrm{Na}^{+}\right.$, and $\left.\mathrm{HCO}_{3}{ }^{-}\right)$in the 


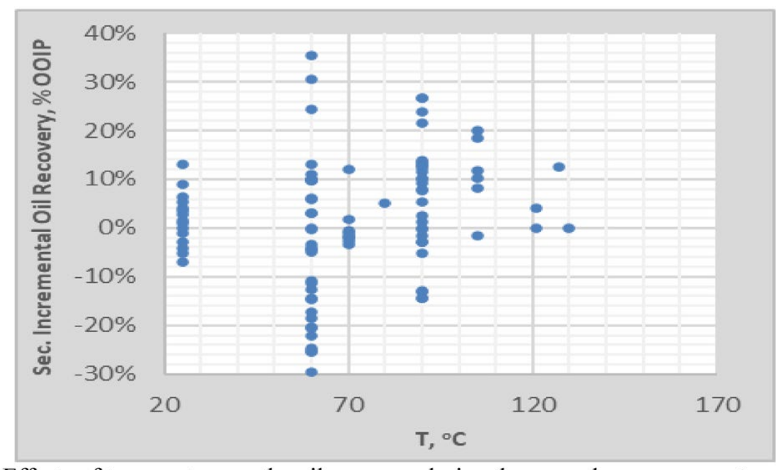

a Effects of temperature on the oil recovery during the secondary recovery stage

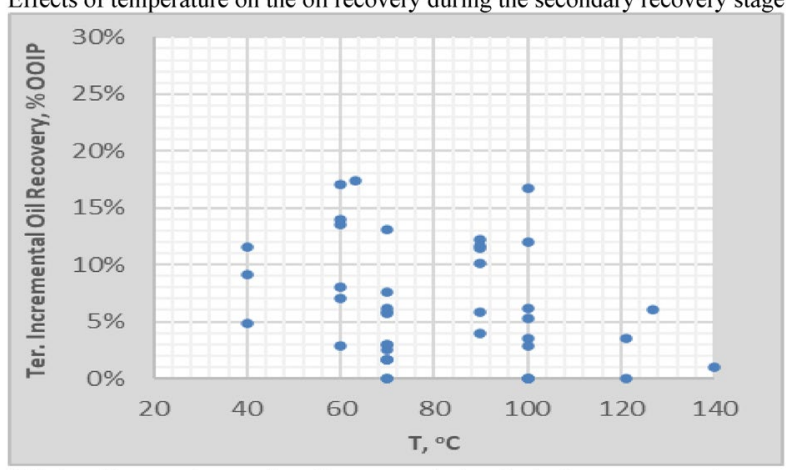

b Effects of temperature on the oil recovery during the tertiary recovery stage

Fig. 11 Incremental oil recovery versus temperature in the secondary and tertiary recovery stages

LS injected water appear to be the most effective parameters in the tertiary LSWF.

As shown in Fig. 13 a, b the statistical analysis without considering the rock minerals showed that the $\mathrm{SO}_{4}{ }^{2-}$ concentration of the HS is the highest effective parameter. The anhydrite dissolution is one of the sources for the in situ $\mathrm{SO}_{4}{ }^{2-}$. Therefore, while considering rock minerals, the effect of anhydrite seems to be the most dominant parameter.

It is obviously clear that the results of the statistical analysis are matched with the previous discussion in the previous sections. All results indicate that the composition of the injected water is more important than its salinity. In addition, it was found that changing the water composition regardless of its salinity can increase oil recovery in both secondary and tertiary recovery stages.

\section{Summary and conclusions}

In this work, a comprehensive review and analysis were conducted to derive new findings and screening criteria for waterflooding projects' applications in the carbonate reservoirs. Based on the results of this study, the following conclusions can be made:

- Wettability alteration by LSWF in the carbonate reservoirs is a very complicated mechanism.

- There are various factors that affect the WF process in the carbonate reservoirs, such as water composition, oil composition, reservoir rock properties, and temperature.

- The salinity value of the injected water appears to have an insignificant effect on oil recovery. However, water composition is the key parameter for successful waterflooding (WF) projects.

- Adjusting injected water composition (when cost allows) can improve oil recovery up to $30 \%$.
Fig. 12 Pareto chart for the statistical analysis of the results of the secondary recovery stage without considering the rock minerals

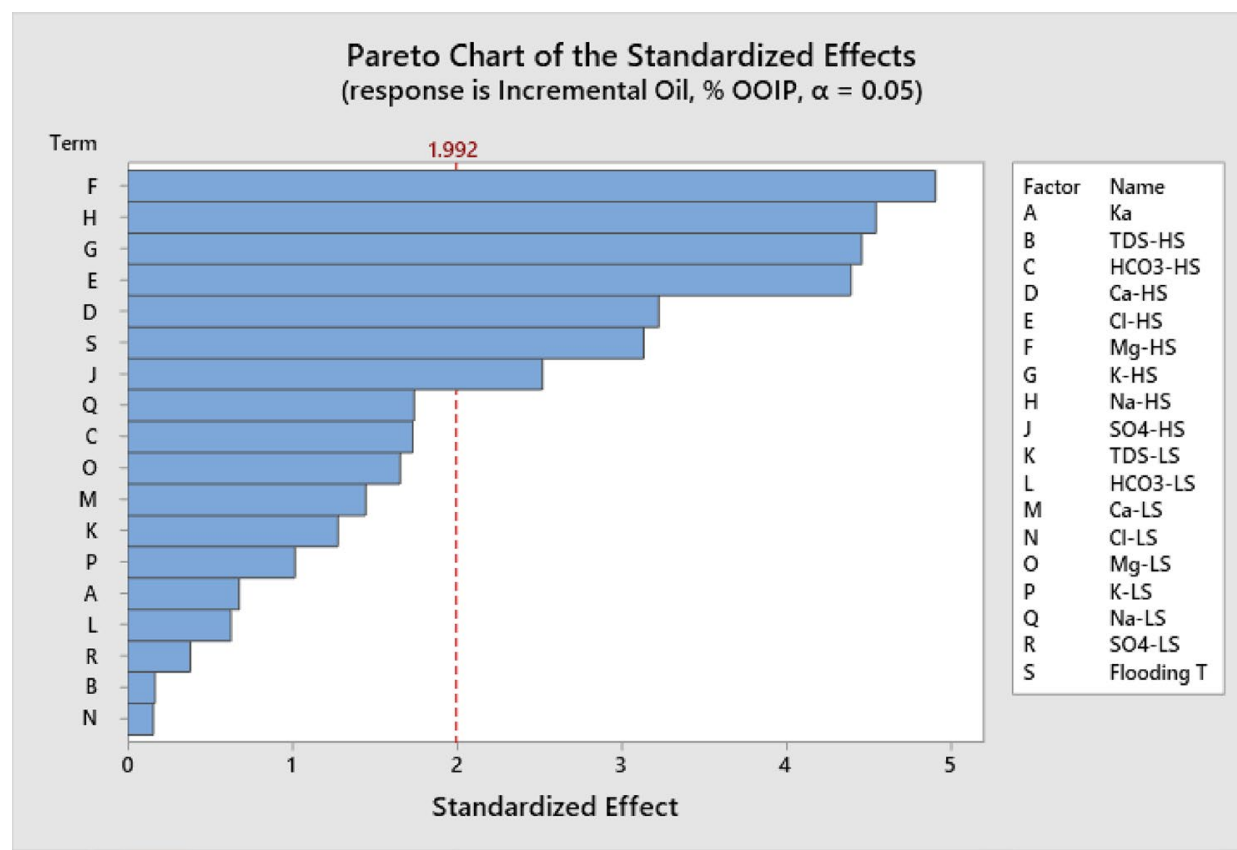


Fig. 13 a Pareto chart for the statistical analysis of the results of the tertiary recovery stage without considering the rock minerals. b Pareto chart for the statistical analysis of the results of the tertiary recovery stage with considering the rock minerals

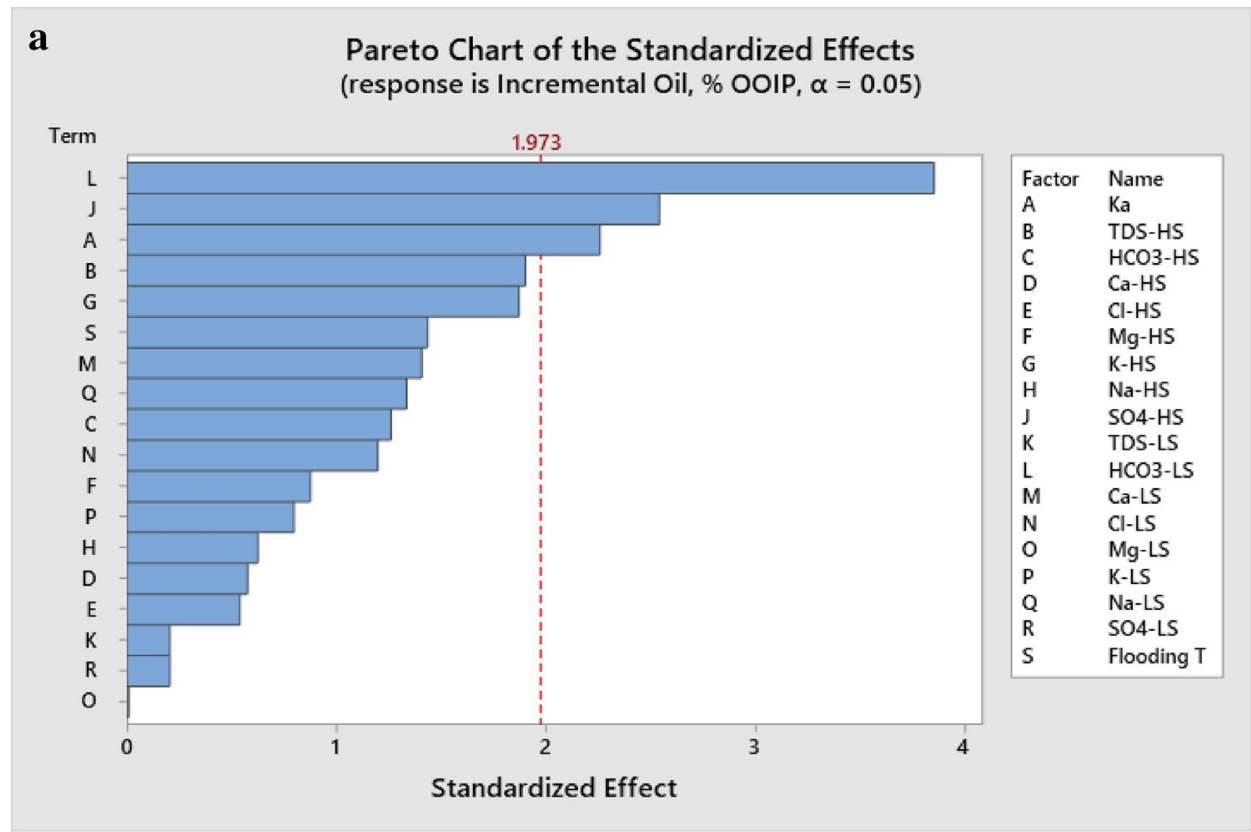

b

Pareto Chart of the Standardized Effects (response is Incremental Oil, \% OOIP, $\alpha=0.05$ )

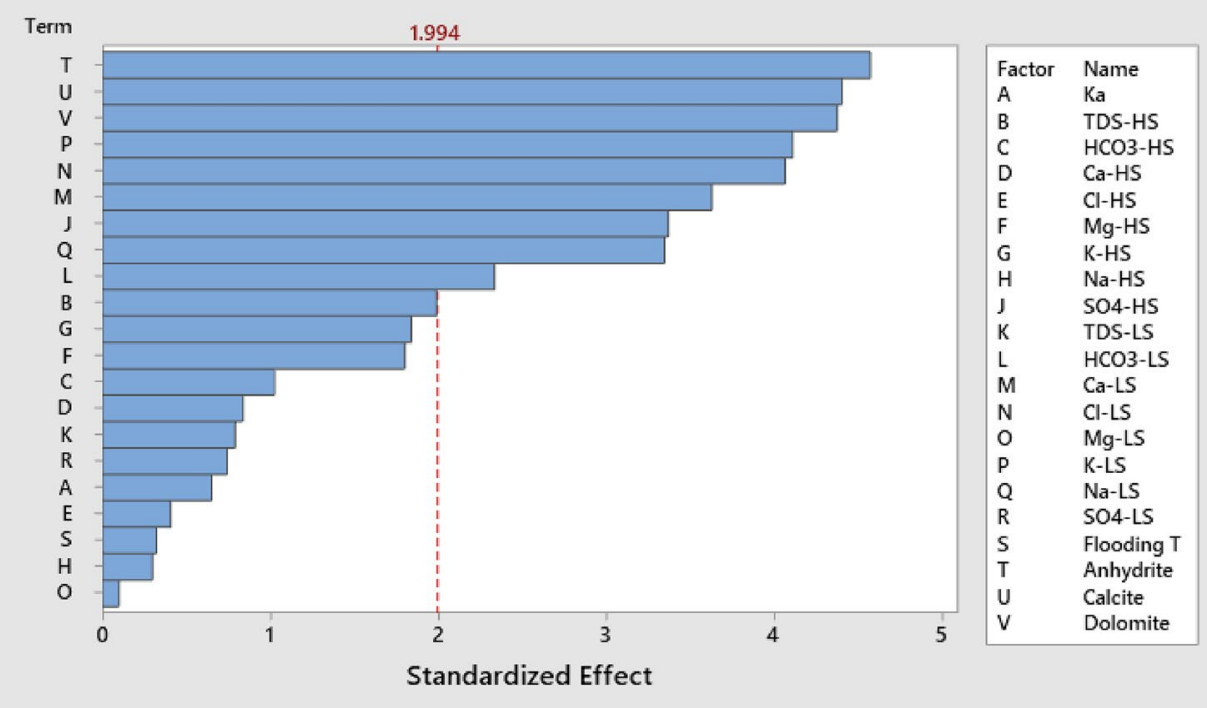

- Changing water salinity from LSWF to HSWF can also lead to incremental oil recovery up to $18 \%$ in the tertiary recovery stage.

- Applying the optimum salinity and composition WF in the secondary recovery stage is more effective than applying it in the tertiary recovery stage.

- The greatest influence parameters in the secondary recovery stage are the concentrations of $\mathrm{Mg}^{2+}, \mathrm{Na}^{+}, \mathrm{K}^{+}$, and $\mathrm{Cl}^{-}$in the injected water.
- The most dominant parameters in the tertiary recovery stage are the rock minerals and the concentration of $\mathrm{K}^{+}$, $\mathrm{HCO}_{3}^{-}$, and $\mathrm{SO}_{4}{ }^{2-}$ in the injected water.

- The effects of $\mathrm{HCO}_{3}{ }^{-}$and Iodide have not been well studied in the literature and need further investigation.

- There are no clear relations between the incremental oil recovery and oil properties (TAN and BAN) in both secondary and tertiary recovery stages.

- Incremental oil recovery values were documented in all ranges of flooding temperatures. 
- It is technically difficult to introduce a unique composition in LSWF for wettability alteration for all types of rocks. Experimental work for each specific reservoir is essential for determining the optimum composition. "LSWF is a specific process for a specific reservoir."

Funding This work was executed through an unfunded research project at Cairo University (Egypt).

\section{Declarations}

Conflict of interest On behalf of all authors, I state that there is no conflict of interest.

Open Access This article is licensed under a Creative Commons Attribution 4.0 International License, which permits use, sharing, adaptation, distribution and reproduction in any medium or format, as long as you give appropriate credit to the original author(s) and the source, provide a link to the Creative Commons licence, and indicate if changes were made. The images or other third party material in this article are included in the article's Creative Commons licence, unless indicated otherwise in a credit line to the material. If material is not included in the article's Creative Commons licence and your intended use is not permitted by statutory regulation or exceeds the permitted use, you will need to obtain permission directly from the copyright holder. To view a copy of this licence, visit http://creativecommons.org/licenses/by/4.0/.

\section{References}

Abdelhamid M, Elnaggar O (2017) Investigating the relation between oil recovery factor in carbonate oil reservoirs and injected water salinity. In: Paper presented at the offshore mediterranean conference and exhibition, 2017, March 29-31. OMC-2017-539

Abdeli DZ, Seiden AB (2018) High-performance water treatment technology for the reservoir pressure maintenance at oil fields. J Mech Eng Res Dev 41(4):66-81. https://doi.org/10.1007/ s13202-019-0650-9

Aksulu H, Håmsø D, Strand S, Puntervold T, Austad T (2012) Evaluation of low-salinity enhanced oil recovery effects in sandstone: effects of the temperature and $\mathrm{pH}$ gradient. Energy Fuels 26(6):3497-3503. https://doi.org/10.1021/ef300162n

Al Hamad M, AlZoukani A, Ali F, Badri M, Wael A (2017) Dynamic waterflooding in carbonates: the role of iodide ions. In: Paper presented at the SPE Kingdom of Saudi Arabia annual technical symposium and exhibition, Dammam, Saudi Arabia, 2017 April 24-27. SPE-188026-MS. https://doi.org/10.2118/ 188026-MS

Al Harrasi A, Al-maamari RS, Masalmeh SK (2012) Laboratory investigation of low salinity waterflooding for carbonate reservoirs. In: The paper was presented at the Abu Dhabi international petroleum conference and exhibition, Abu Dhabi, UAE, 2012. November 11-14. SPE-161468-MS. https://doi.org/10.2118/161468-MS

Al Shalabi EW, Sepehrnoori K (2017) Low salinity and engineered water injection for sandstone and carbonate reservoirs. Gulf Professional Publishing
Al-adasani A, Bai B, Wu YS (2012) Investigating low salinity waterflooding recovery mechanisms in carbonate reservoirs. In: Paper presented at SPE EOR conference at oil and gas West Asia. Muscat, Oman. 2012, 16-18 April. SPE-155560-MS. https://doi.org/ 10.2118/155560-MS

Alameri W, Teklu TW, Graves RM, Kazemi H, AlSumaiti AM (2014) Wettability alteration during low salinity waterflooding in carbonate reservoir cores. In: Paper presented at the SPE Asia Pacific oil and gas conference and exhibition, Adelaide, Australia, 2014. October 14-16. SPE-171529-MS. https://doi.org/10.2118/ 171529-MS

Al-Attar HH, Mahmoud MY, Zekri AY, Almehaideb R, Ghannam M (2013) Low-salinity flooding in a selected carbonate reservoir: experimental approach. J Pet Explor Prod Technol 3:139-149. https://doi.org/10.1007/s13202-013-0052-3

Ali AY, Al-Saleh S, Al-Jawfi M (2012) Improved/enhanced oil recovery from carbonate reservoirs by tuning injection water salinity and ionic content. In: Paper presented at the SPE improved oil recovery symposium, 2012, April 14-18. SPE-154076-MS. https://doi.org/10.2118/154076-MS

Al-Khafaji A, Neville A, Wilson M, Wen D (2017) Effect of low salinity on the oil desorption efficiency from calcite and silica surfaces. Energy Fuels 31(11):11892-11901. https://doi.org/10.1021/acs. energyfuels.7b02182

Almeida SBD, Winter A. Pires LO, Trevisan OV (2019) Wettability alteration in carbonate rocks by the low salinity water using a high-speed centrifuge. In: Paper presented at the offshore technology conference Brasil, Rio de Janeiro, Brazil, 2019, October 29-31. OTC-29868-MS. https://doi.org/10.4043/29868-MS

Alotaibi MB, Nasr-El-Din HA (2009) Chemistry of injection water and its impact on oil recovery in carbonate and clastics formations. In: Paper presented at the SPE international symposium on oilfield chemistry, The Woodlands. Texas, 2009, April 20-22. SPE-121565-MS. https://doi.org/10.2118/121565-MS

AlQuraishi Abdulrahman A, AlHussinan Saud N, Hamdan Q (2015) AlYami. Efficiency and recovery mechanisms of low salinity water flooding in sandstone and carbonate reservoirs. In: Paper presented at the offshore mediterranean conference and exhibition, Ravenna, Italy, 2015, March 25-27. OMC-2015-223

Al-Shalabi EW, Sepehrnoori K, Pope G (2015) Geochemical interpretation of low salinity water injection in carbonate oil reservoirs. SPE J 20(6):1212-1226. https://doi.org/10.2118/169101-PA

Al-Shalabi EW, Sepehrnoori K, Pope G, Mohanty K (2014) A fundamental model for predicting oil recovery due to low salinity water injection in carbonate rocks. In: Paper presented at the SPE energy resources conference, Port of Spain, Trinidad, and Tobago, 2014. June 9-11. SPE-169911-MS. https://doi.org/10. 2118/SPE-169911-MS

Alvarado V, Garcia-Olvera G, Hoyer P, Lehmann TE (2014) Impact of polar components on crude oil-water interfacial film formation: a mechanisms for low-salinity waterflooding. In: Paper presented at the SPE annual technical conference and exhibition, Amsterdam, The Netherlands, 2014. October 27-29. SPE-170807-MS. https:// doi.org/10.2118/170807-MS

Amirian T, Haghighi M, Mostaghimi P (2017) Pore scale visualization of low salinity water flooding as an enhanced oil recovery method. Energy Fuels 31(12):13133-13143. https://doi.org/10.1021/acs. energyfuels.7b01702

Arnold BC (2014) Pareto distribution. Wiley Stats Ref: Statistics Reference Online. 1-10. https://doi.org/10.1002/9781118445112.stat0 1100.pub2

Austad T, Shariatpanahi S, Strand S, Black C, Webb K (2011) Conditions for a low-salinity enhanced oil recovery (EOR) effect in carbonate oil reservoirs. Energy Fuels 26:569-575. https://doi. org/10.1021/ef201435g

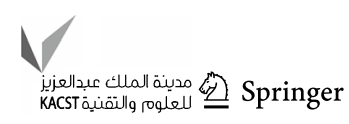


Austad T, Shariatpanahi SF, Strand S, Black CJJ, Webb KJ (2012) Conditions for a low-salinity enhanced oil recovery (EOR) effect in carbonate oil reservoirs. Energy Fuels 26(1):569-575. https:// doi.org/10.1021/ef201435g

Austad T, Shariatpanahi SF, Strand S, Aksulu H, Puntervold T (2015) Low salinity EOR effects in limestone reservoir cores containing anhydrite: a discussion of the chemical mechanism. Energy Fuels 29(11):6903-6911. https://doi.org/10.1021/acs.energyfuels. $5 \mathrm{~b} 01099$

Austad T, Strand S, Høgnesen EJ, Zhang P (2005) Seawater as IOR fluid in fractured chalk. In: Paper presented at SPE international symposium on oilfield chemistry. The Woodlands, Texas. 2005, February 2-4. SPE-93000-MS. https://doi.org/10.2118/93000-MS

Austad T, Strand S, Madland MV, Puntervold T, Korsnes RI (2007) Seawater in chalk: an EOR and compaction fluid. In: Paper presented at the international petroleum technology conference, Dubai, U.A.E., 2007, 4-6 December. IPTC-11370-MS. https:// doi.org/10.2523/IPTC-11370-MS

Austad T, RezaeiDoust A, Puntervold T (2010) Chemical mechanism of low salinity water flooding in sandstone reservoirs. In: Paper presented at SPE improved oil recovery symposium. 2010. April 24-28. Tulsa, Oklahoma, USA. SPE-129767-MS. https://doi.org/ 10.2118/129767-MS

Bagci S, Kok MV, Turksoy U (2001) Effect of brine composition on oil recovery by waterflooding. Pet Sci Technol 19(3-4):359-372. https://doi.org/10.1081/LFT-100000769

Bartels WB, Mahani H, Berg S, Menezes R, van der Hoeven JA, Fadili A (2017) Oil configuration under high-salinity and low-salinity conditions at pore scale: a parametric investigation by use of a single-channel micromodel. SPE J 22(05):1-362. https://doi.org/ 10.2118/181386-PA

Bartels WB, Mahani H, Berg S, Hassanizadeh SM (2019) Literature review of low salinity waterflooding from a length and time scale perspective. Fuel 236:338-353. https://doi.org/10.1016/j.fuel. 2018.09.018

Bazhanova M, Pourafshary P (2020) Impact of SO $42-$, Ca 2+, and $\mathrm{Mg} 2+$ ions in Caspian Sea ion-engineered water on the rate of wettability alteration in carbonates. J Pet Explor Prod Technol 10(8):3281-3293. https://doi.org/10.1007/s13202-020-01006-z

Bernard GG (1967) Effect of floodwater salinity on recovery of oil from cores containing clays. In: Paper presented at the SPE California regional meeting, Los Angeles, California, 1967, 26-27 October. SPE-1725-MS. https://doi.org/10.2118/1725-MS

Camargo C, Vidal Vargas JA, Ruidiaz E, Winter A, Koroishi E, Vidal Trevisan O, Soares Bassani G (2019) Study of the effect of low salinity water injection on the oil recovery factor in fractured carbonate rocks using computed tomography. In: Paper presented at the offshore technology conference Brasil, 2019, October 29-31. OTC-29939-MS. https://doi.org/10.4043/29939-MS

Chávez-Miyauchi TE, Firoozabadi A, Fuller GG (2016) Nonmonotonic elasticity of the crude oil-brine interface in relation to improved oil recovery. Langmuir 32(9):2192-2198. https://doi.org/10.1021/ acs.langmuir.5b04354

Derkani MH, Fletcher AJ, Abdallah W, Sauerer B, Anderson J, Zhang ZJ (2018) Low salinity waterflooding in carbonate reservoirs: review of interfacial mechanisms. Colloids Interfaces 2(2):20. https://doi.org/10.3390/colloids2020020

Dordzie G, Dejam M (2021) Enhanced oil recovery from fractured carbonate reservoirs using nanoparticles with low salinity water and surfactant: a review on experimental and simulation studies. Adv Coll Interface Sci. https://doi.org/10.1016/j.cis.2021.102449

Emadi A, Sohrabi M (2012) Visual investigation of low salinity waterflooding. In: Paper presented at the SPE annual technical conference and exhibition, 2012, September 30-October 2. SPE166435-MS. https://doi.org/10.2118/166435-MS
Evje S, Hiorth A (2010) A mathematical model for dynamic wettability alteration controlled by water-rock chemistry. NHM 5(2):217256. https://doi.org/10.3934/nhm.2010.5.217

Fathi SJ, Austad T, Strand S (2010) "Smart water" as a wettability modifier in chalk: the effect of salinity and ionic composition. Energy Fuels 24(4):2514-2519. https://doi.org/10.1021/ef901 $304 \mathrm{~m}$

Fathi SJ, Austad T, Strand S (2012) Water-based enhanced oil recovery (EOR) by" Smart Water" in carbonate reservoirs. In: Paper presented at the SPE EOR conference at oil and gas West Asia, Muscat, Oman, 2012. April 16-18. SPE-154570-MS. https://doi. org/10.2118/154570-MS

Fredriksen SB, Rognmo AU, Fernø MA (2018) Pore-scale mechanisms during low salinity waterflooding: oil mobilization by diffusion and osmosis. J Petrol Sci Eng 163:650-660. https://doi.org/10. 1016/j.petrol.2017.10.022

Fredriksen SB, Rognmo AU, Fernø MA (2016) Pore-scale mechanisms during low salinity waterflooding: water diffusion and osmosis for oil mobilization. In: Paper presented at the SPE Bergen one day seminar, Grieghallen, Bergen, Norway, 2016, 20 April. SPE180060-MS. https://doi.org/10.2118/180060-MS

Gandomkar A, Rahimpour MR (2015) Investigation of low salinity waterflooding in secondary and tertiary enhanced oil recovery in limestone reservoirs. Energy Fuels 29(12):7781-7792. https://doi. org/10.1021/acs.energyfuels.5b01236

Ghandi E, Parsaei R, Riazi M (2019) Enhancing the spontaneous imbibition rate of water in oil-wet dolomite rocks through boosting a wettability alteration process using carbonated smart brines. Pet Sci 16(6):1361-1373. https://doi.org/10.1007/s12182-019-0355-1

Gopani PH, Singh N, Sarma HK, Mattey P, Srivastava VR (2021) Role of monovalent and divalent ions in low-salinity water flood in carbonate reservoirs: an integrated analysis through zeta potentiometric and simulation studies. Energies 14(3):729. https://doi. org/10.3390/en14030729

Gunst RF, Mason RL (2009) Fractional factorial design. Wiley Interdiscip Rev Comput Stat 1(2):234-244. https://doi.org/10.1002/ wics. 27

Hamouda AA, Maevskiy E (2014) Oil recovery mechanism (s) by low salinity brines and their interaction with chalk. Energy Fuels 28(11):6860-6868. https://doi.org/10.1021/ef501688u

Hiorth A, Cathles LM, Kolnes J, Vikane O, Lohne A, Madland MVA (2008) Chemical model for the seawater- $\mathrm{CO}_{2}$-carbonate systemaqueous and surface chemistry. In: Paper presented at the wettability conference held in Abu Dhabi, UAE (pp. 27-28). 2008. 29 October 29-2 November

Hognesen EJ, Strand S, Austad T (2005) Waterflooding of preferential oil-wet carbonates: Oil recovery related to reservoir temperature and brine composition. In: Paper presented at the SPE Europec/ EAGE annual conference, Madrid, Spain, 2005, June 13-16. SPE94166-MS. https://doi.org/10.2118/94166-MS

Hosseini E, Chen Z, Sarmadivaleh M, Mohammadnazar D (2020) Applying low-salinity water to alter wettability in carbonate oil reservoirs: an experimental study. J Pet Explor Prod Technol. https://doi.org/10.1007/s13202-020-01015-y

Jiang H, Chopping CG, Forsman C, Xie X (2014) Lab observation of low salinity waterflooding for a phosphoria reservoir rock. In: Paper presented at the SPE Western North American and rocky mountain joint meeting, Denver, Colorado. 2014, April 17-18. SPE-169546-MS. https://doi.org/10.2118/169546-MS

Lager A, Webb KJ, Black CJJ, Singleton M, Sorbie KS (2008) Low salinity oil recovery-an experimental investigation1. Petrophysics. $49(01)$

Ligthelm D, Gronsveld J, Hofman J, Brussee N, Marcelis F, Van der Linde H (2009) Novel waterflooding strategy by manipulation of injection brine composition. In: Paper presented at the SPE EUROPEC/EAGE Conference and Exhibition. Amsterdam, The 
Netherlands. 2009, 8-11 June. SPE-119835. https://doi.org/10. 2118/119835-MS

Liu X, Yan W, Stenby EH, Thormann E (2016) Release of crude oil from silica and calcium carbonate surfaces: on the alternation of surface and molecular forces by high-and low-salinity aqueous salt solutions. Energy Fuels 30(5):3986-3993. https://doi.org/10. 1021/acs.energyfuels.6b00569

Mahani H, Keya AL, Berg S, Bartels WB, Nasralla R, Rossen WR (2015) Insights into the mechanism of wettability alteration by low-salinity flooding (LSF) in carbonates. Energy Fuels 29:13521367. https://doi.org/10.1021/ef5023847

Mahani H, Keya AL, Berg S, Nasralla R (2018) Electrokinetics of carbonate/brine interface in low-salinity waterflooding: Effect of brine salinity, composition, rock type, and $\mathrm{pH}$ on $\zeta$-potential and a surface-complexation model. SPE J 22(01):53-68. https://doi. org/10.2118/181745-PA

Mahzari P, Sohrabi M (2014) Crude oil/brine interactions and spontaneous formation of micro-dispersions in low salinity water injection. In: Paper presented at the SPE improved oil recovery symposium, Tulsa, Oklahoma, USA, 2014, April 12-16. SPE169081-MS. https://doi.org/10.2118/169081-MS

Masalmeh S, Al-Hammadi M, Farzaneh A, Sohrabi M (2019) Low salinity water flooding in carbonate: screening, laboratory quantification and field implementation. In: Paper presented at the Abu Dhabi international petroleum exhibition and conference, Abu Dhabi, UAE, 2019, November 11-14. SPE-197314-MS. https:// doi.org/10.2118/197314-MS

Maskari NSA, Sari A, Hossain MM, Saeedi A, Xie Q (2020) Response of non-polar oil component on low salinity effect in carbonate reservoirs: adhesion force measurement using atomic force microscopy. Energies 13(1):77. https://doi.org/10.3390/en13010077

McGuire P, Chatham J, Paskvan F, Sommer D, Carini F (20015) Low salinity oil recovery: an exciting new EOR opportunity for Alaska's North Slope. In: Presented at proceedings of the society of petroleum engineers western regional meeting, Irvine, CA, USA, 2005, 30 March-1 April. SPE-93903-MS. https://doi.org/10.2118/ 93903-MS

Minitab, LLC. Getting started with Minitab statistical software. Software manual, Minitab, 2020. LLC, USA

Mohsenzadeh A, Pourafshary P, Al-Wahaibi Y (2016) Oil recovery enhancement in carbonate reservoirs via low saline water flooding in presence of low concentration active ions: a case study. In: Paper presented at the SPE EOR conference at oil and gas West Asia. Muscat, Oman. 2016, March 21-23. Paper Number: SPE179767-MS. DOI: https://doi.org/10.2118/179767-MS

Mozaffari S, Ghasemi H, Tchoukov P, Czarnecki J, Nazemifard N (2021) Lab-on-a-chip systems in asphaltene characterization: a review of recent advances. Energy Fuels. https://doi.org/10.1021/ acs.energyfuels. $1 \mathrm{c} 00717$

Myint PC, Firoozabadi A (2015) Thin liquid films in improved oil recovery from low-salinity brine. Curr Opin Colloid Interface Sci 20:105-114. https://doi.org/10.1016/j.cocis.2015.03.002

Nasralla RA, Sergienko E, Masalmeh SK, van der Linde HA, Brussee NJ, Mahani H, Alqarshubi I (2014) Demonstrating the potential of low-salinity waterflood to improve oil recovery in carbonate reservoirs by qualitative core flood. In: Paper presented at Abu Dhabi international petroleum exhibition and conference, 2014. https://doi.org/10.2118/172010-MS

Okasha TM, Alshiwaish A (2009) Effect of brine salinity on interfacial tension in Arab-D carbonate reservoir, Saudi Arabia. In: Paper presented at the SPE Middle East oil and gas show and conference. March 15-18. Manama, Bahrain. SPE-119600-MS. DOI: https://doi.org/10.2118/119600-MS

Olayiwola SO, Dejam M (2021) Comprehensive experimental study on the effect of silica nanoparticles on the oil recovery during alternating injection with low salinity water and surfactant into carbonate reservoirs. J Mol Liq 325:115178. https://doi.org/10. 1016/j.molliq.2020.115178

Den Ouden L, Nasralla RA, Guo H, Bruining H, Van Kruijsdijk CPJW (2015) Calcite dissolution behavior during low salinity water flooding in carbonate rock. In: IOR 2015-18th European symposium on improved oil recovery (pp. cp-445). European Association of Geoscientists and Engineers.] https://doi.org/10.3997/ 2214-4609.201412102

Plackett RL, Burman JP (1946) The design of optimum multifactorial experiments. Biometrika 33(4):305-325. https://doi.org/10. 2307/2332195

Pu H, Xie X, Yin P, Morrow NR (2008) Application of coalbed methane water to oil recovery from tensleep sandstone by low salinity waterflooding. In: Paper presented at the SPE improved oil recovery symposium, Tulsa, Oklahoma, USA, 2008, 20-23 April. SPE-113410-MS. https://doi.org/10.2118/113410-MS

Puntervold T (2008) Waterflooding of carbonate reservoirs: EOR by wettability alteration. Ph.D. Thesis, 2008. University of Stavanger, Stavanger, Norway

Romanuka J, Hofman J, Ligthelm DJ, Suijkerbuijk B, Marcelis F, Oedai S, Austad T (2012) Low salinity EOR in carbonates. In: Paper presented at SPE annual technical conference and exhibition. San Antonio, Texas. 2012. 5-8 October. SPE-153869-MS. https://doi. org/10.2118/38795-MS

Sandengen K, Kristoffersen A, Melhuus K, Jøsang LO (2016) Osmosis as mechanism for low-salinity enhanced oil recovery. SPE J 21(04):1-227. https://doi.org/10.2118/179741-PA

Sandengen K, Arntzen OJ (2013) Osmosis during low salinity water flooding. In: Paper presented at IOR 2013-17th European symposium on improved oil recovery. (pp. cp-342). European Association of Geoscientists and Engineers. https://doi.org/10.3997/ 2214-4609.20142608

Sari A, Xie Q, Chen Y, Saeedi A, Pooryousefy E (2017) Drivers of low salinity effect in carbonate reservoirs. Energy Fuels 31(9):89518958. https://doi.org/10.1021/acs.energyfuels.7b00966

Sari A (2020) Wettability alteration during low salinity water flooding in carbonate reservoirs: an experimental and theoretical study. Doctoral dissertation, 2020. Curtin University.' http://hdl.handle. net/20.500.11937/81285

Sarvestani AD, Ayatollahi S, Moghaddam MB (2019) Smart water flooding performance in carbonate reservoirs: an experimental approach for tertiary oil recovery. J Pet Explor Prod Technol 9(4):2643-2657. https://doi.org/10.1007/s13202-019-0650-9

Shaker Shiran B, Skauge A (2013) Enhanced oil recovery (EOR) by combined low salinity water/polymer flooding. Energy Fuels 27(3):1223-1235. https://doi.org/10.1021/ef301538e

Shariatpanahi SF, Strand S, Austad T (2011a) Initial wetting properties of carbonate oil reservoirs: effect of the temperature and presence of sulfate in formation water. Energy Fuels 25(7):3021-3028. https://doi.org/10.1021/ef200033h

Shechter J, Atzin N, Mozaffari A, Zhang R, Zhou Y, Strain B, Ross JL (2020) Direct observation of liquid crystal droplet configurational transitions using optical tweezers. Langmuir 36(25):7074-7082. https://doi.org/10.1021/acs.langmuir.9b03629

Snosy MF, El Ela MA, El-Banbi A, Sayyouh H (2020) Comprehensive investigation of low salinity waterflooding in sandstone reservoirs. J Pet Explor Prod Technol 10(5):2019-2034. https://doi.org/10. 1007/s13202-020-00862-Z

Snosy MF, El Ela MA, El-Banbi A, Sayyouh H (2021) Impact of the injected water salinity on oil recovery from sandstone formations: application in an Egyptian oil reservoir. Petroleum. https://doi.org/ 10.1016/j.petlm.2021.03.006

Sohal MA, Thyne G, Søgaard EG (2016) Review of recovery mechanisms of ionically modified waterflood in carbonate reservoirs. Energy Fuels 30:1904-1914. https://doi.org/10.1021/acs.energ yfuels.5b02749

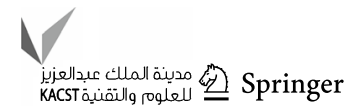


Sohrabi M, Mahzari P, Farzaneh SA, Mills JR, Tsolis P, Ireland S (2017) Novel insights into mechanisms of oil recovery by use of low-salinity-water injection. Soc Pet Eng J 22:407-416. https:// doi.org/10.2118/172778-PA

Strand S, Austad T, Puntervold T, Høgnesen EJ, Olsen M, Barstad SMF (2008) "Smart water" for oil recovery from fractured limestone: a preliminary study. Energy Fuels 22(5):3126-3133. https://doi. org/10.1021/ef800062n

Tang GQ, Morrow NR (1997) Salinity, temperature, oil composition, and oil recovery by waterflooding. SPE Res Eng 12(4):269-276. https://doi.org/10.2118/36680-PA

Tetteh JT, Rankey E, Barati R (2017) Low salinity waterflooding effect: crude oil/brine interactions as a recovery mechanism in carbonate rocks. In: Paper presented at the OTC Brasil, Rio de Janeiro, Brazil, 2017, October 24-26. OTC-28023-MS. https://doi.org/10. 4043/28023-MS

Uetani T, Kaido H, Yonebayashi H (2019) Investigation of anhydrite dissolution as a potential low salinity waterflooding mechanism using carbonate reservoir rocks. In: Paper presented at the international petroleum technology conference, Beijing, China. 2019, March 26-28. IPTC-19133-MS. https://doi.org/10.2523/ IPTC-19133-MS

Uetani T, Kaido H, Yonebayashi H (2020) Effect of total acid number and recovery mode on low salinity eor in carbonates. In: Paper presented at the Abu Dhabi international petroleum exhibition and conference, 2020. November 9-12. SPE-203281-MS. DOI: https://doi.org/10.2118/203281-MS

Vijapurapu CS, Rao DN (2003) Effect of brine dilution and surfactant concentration on spreading and wettability.] In: Paper presented at the international symposium on oil field chemistry. Houston, Texas. 2003, February 5-7. SPE-80273-MS. https://doi.org/10. 2118/80273-MS

Yi Z, Sarma HK (2012) Improving waterflood recovery efficiency in carbonate reservoirs through salinity variations and ionic exchanges: a promising low-cost "smart-waterflood" approach. In: Paper presented at proceedings of the Abu dhabi international petroleum conference and exhibition, Abu Dhabi, UAE. 2012, 11-14 November.SPE-161631-MS. https://doi.org/10.2118/ 161631-MS

Yousef Ali A, Al-Saleh S, Al-Kaabi A, Mohammed A-J (2010) Laboratory investigation of novel oil recovery method for carbonate reservoirs. In: Paper presented at the Canadian unconventional resources and international petroleum conference, Calgary,
Alberta, Canada, 2010, October 19 -21. SPE-137634-MS. https:// doi.org/10.2118/137634-MS

Yousef AA, Al-Salehsalah SH, Al-Jawfi MS (2011) New recovery method for carbonate reservoirs through tuning the injection water salinity: smart waterflooding. In: Paper presented at the EUROPEC/EAGE annual conference and exhibition. Vienna, Austria. 2011, 23-26 May. SPE-143550-MS. https://doi.org/10. 2118/143550-MS

Zahid A, Shapiro AA, Skauge (2012) An experimental studies of low salinity water flooding carbonate: a new promising approach. In: Paper presented at proceedings of the society of petroleum engineers enhanced oil recovery conference at oil and gas West Asia, Muscat, Oman, 2012, 16-18 April. SPE-155625-MS. https://doi. org/10.2118/155625-MS

Zekri AY, Harahap BA, Al-Attar HH, Lwisa EG (2019) Effectiveness of oil displacement by sequential low-salinity waterflooding in low-permeability fractured and non-fractured chalky limestone cores. J Pet Explor Prod Technol 9(1):271-280. https://doi.org/ 10.1007/s13202-018-0478-8

Zhang P, Austad T (2006) Wettability and oil recovery from carbonates: effects of temperature and potential determining ions. Colloids Surf A 279(1-3):179-187. https://doi.org/10.1016/j.colsu rfa.2006.01.009

Zhang DL, Liu S, Puerto M, Miller CA, Hirasaki GJ (2006) Wettability alteration and spontaneous imbibition in oil-wet carbonate formations. J Pet Sci Eng 52(1-4):213-226

Zhang P, Austad T (2005) Waterflooding in Chalk-relationship between oil recovery, new wettability index, brine composition and cationic wettability modifier. In: Paper presented at the international petroleum technology conference, Doha, Qatar. November 21-23. IPTC-10506-MS. https://doi.org/10.3997/2214-4609pdb.1.D036

Zoshchenko O, Aleshchenko A, Trushin Y (2019) Assessment of the potential of low-salinity water injection technology to increase the oil recovery of the carbonate reservoir of the kharyaga field. In: Paper presented at the SPE Russian petroleum technology conference. SPE-196764-MS. https://doi.org/10.2118/196764-MS

Publisher's Note Springer Nature remains neutral with regard to jurisdictional claims in published maps and institutional affiliations. 